Check for updates

Cite this: RSC Adv., 2019, 9, 30599

Received 11th July 2019

Accepted 10th September 2019

DOI: $10.1039 / c 9 r a 05298 d$

rsc.li/rsc-advances

\title{
Recent progress in development of 2,3- diaminomaleonitrile (DAMN) based chemosensors for sensing of ionic and reactive oxygen species $\uparrow$
}

\author{
Aruna, Bhawna Rani, Suman Swami, Arunava Agarwala, ${ }^{\star}$ Debasis Behera \\ and Rahul Shrivastava (D)*
}

\begin{abstract}
2,3-Diaminomaleonitrile (DAMN) has proved to be a valuable organic $\pi$-conjugated molecule having many applications in the area of chemosensors for sensing of ionic and neutral species because of its ability to act as a building block for well-defined molecular architectures and scaffolds for preorganised arrays of functionality. In this article, we discussed the utilization of 2,3-diaminomaleonitrile (DAMN) for the design and development of chemosensor molecules and their application in the area of metal ion, anion and reactive oxygen species sensing. Along with these, we present different examples of DAMN based chemosensors for multiple ion sensing. We also discuss the ion sensing mechanism and potential uses in other related areas of research.
\end{abstract}

\section{Introduction}

The design and development of chemosensor molecules mainly rely on the concepts of complementarity, co-cooperativity and preorganization. ${ }^{1-3}$ Sensor molecules derived from these concepts have a suitable orientation of functional groups which produce strong covalent and non-covalent interactions between sensors and target guest species. ${ }^{4-6}$ Different scaffolds like calixarenes, cyclotriveratrylene, cyclodextrin, borondipyrromethene (BODIPY), naphthalimides, crown-ethers/thiacrown-ethers, resorcinarenes etc. were successfully used for designing chemosensor molecules for sensing of specific ions and neutral species. These sensor molecules are developed in such a way that they can be functional in a competitive aqueous medium for wide applications in medical, biological and environmental domains..$^{7-9}$ These chemosensor molecules exhibit specific photophysical properties like absorption of light at longer wavelength which facilitates naked eye detection of target species and interesting photoluminescence properties with high quantum yield. ${ }^{10-17}$ A general approach for development of optical chemosensors are coupling of signalling and binding sites either directly or through suitable spacer groups. For instance, binding unit binds guest species either through covalent or non-covalent interactions whereas signalling unit exhibits change in spectroscopic properties like colour, absorption maximum or fluorescence intensity upon guest interactions as shown in Fig. $1 .^{18}$

Department of Chemistry, Manipal University Jaipur, VPO-Dehmi-Kalan, Off Jaipur-Ajmer Express Way, Jaipur, Rajasthan, India 303007. E-mail: rahul. shrivastava@jaipur.manipal.edu; arunava.agarwala@jaipur.manipal.edu

$\dagger$ Dedicated to my mother "Smt. Abha Shrivastava".
Diaminomaleonitrile (DAMN) is a unique organic $\pi$-conjugated molecule in which electronic donor parts $\left(-\mathrm{NH}_{2}\right.$ groups $)$ and acceptor parts (-CN group) are linked by a single and double bond. ${ }^{19-21}$ The DAMN has tremendous potential to act as building block in designing of sensor molecules due to its fascinating electronic properties, ${ }^{22,23}$ which can be easily finetuned for sensible sensor design through functionalization by suitable functional group. In last few years, many excellent examples of DAMN based sensors have been published which proved its utility and versatility in research area of designing of molecular sensors. Reviews on different chemical reactions of DAMN as building block for synthesis of heterocyclic entities are previously reported in literature ${ }^{24,25}$ but to the best of our knowledge, reviews on DAMN based sensor molecules for sensing of ions and neutral guest species are still not available in literature. This review will focus on the recent development of DAMN based sensor molecules beginning with short discussion about the discovery and development of chemical structure of DAMN. Examples presented here are mainly grouped according to sensing properties. Finally, sensing mechanism and potential use in other related area of research will be discussed.

\section{Invention and chemical structure and properties of DAMN}

The admittance of DAMN in the chemical world was perceived in 1873 by the efforts of Lange. ${ }^{26} \mathrm{He}$ obtained a black crystalline compound directly from oligomerization of hydrogen cyanide. Thereafter Bedel et al. proposed that resulting black crystalline compound was the tetramer of $\mathrm{HCN}^{27}$ Structure of diaminomaleonitrile had been in suspicion till 1954. In 1955-56, $\mathrm{Webb}^{28}$ and Bredereck ${ }^{29}$ suggested that the diaminomaleonitrile exists as tetramer. They also examined chemistry of 


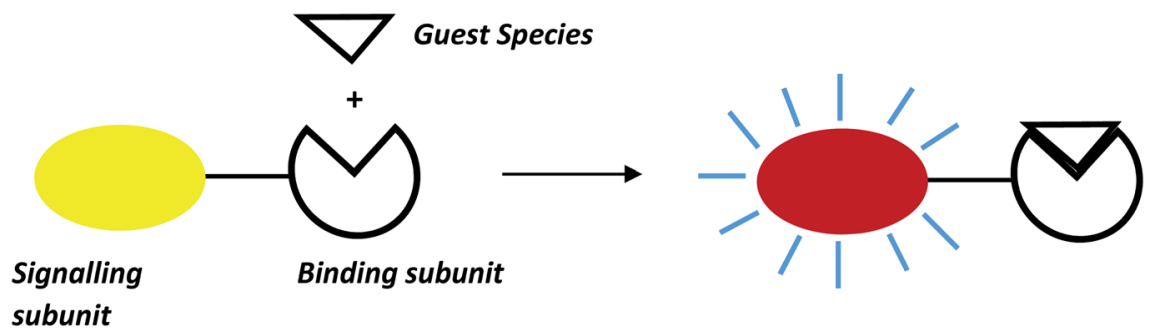

Fig. 1 General approach for designing of chemosensor based on the signalling-binding subunits.

tetramer with the help of infrared and ultraviolet absorption spectrum and concluded that DAMN exist as crystalline tetramer with absence of $\mathrm{C}-\mathrm{H}$ bond. ${ }^{30}$ They carried out dipole moment measurements of DAMN in solution and concluded that molecule exits in cis-conformation (Fig. 2). The cis conformation of DAMN was confirmed by Bredereck from successful synthesis of mono- and di-acetyl derivatives of DAMN. Gryszkiewicz-Trochimowski obtained 2,3-dicyanopyrazine in more than $80 \%$ yield in mild reaction condition by condensation reaction between DAMN with glyoxal which again confirmed cis conformation of DAMN. ${ }^{31}$ Along with this, single crystal X-ray diffraction experiments unambiguously confirmed cis conformation of DAMN in crystalline state. ${ }^{32}$

\section{DAMN based chemosensors for anions}

Anions are necessary for maintaining normal physiological functions of all living organisms due to the involvement of anions in almost every biological operation. Anions also play critical role in different industrial, chemical and environmental processes. Despite their significant role in different biological functions, higher or lower concentration of anions induce different deleterious effects on human health and environment. ${ }^{33}$ Due to deleterious effects of anions, demands of effective chemosensor molecules are drastically increased from last two decades. It was observed that selective sensing of anions with low detection limits are challenging area of research due to their wide range of geometries like spherical, trigonal, tetrahedral, helical and octahedral along with lower charge to radius ratio and tendency of anions to be protonated at low $\mathrm{pH}$ and in protic solvents make sensing of the anions even more difficult.

DAMN is proven as versatile scaffold for designing of sensor molecules for detection of anions due to its unique structural features. In this direction, two diaminomalenonitrile (DAMN) based colorimetric sensor molecules 2-(( $(E)-(9 H$-fluoren-2-yl $)$ methylene)amino)-3-aminomaleonitrile (1) and (E)-2-

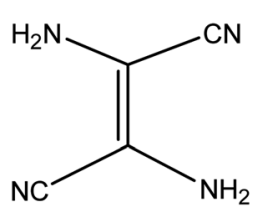

(1)

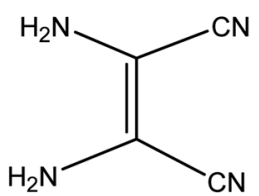

(2)
Fig. 2 Trans and cis conformation of 2,3-diaminomaleonitrile.
(aminoo(((9-ethyl-9H-carbazol-2-yl)methylene)amino)methylene) maleonitrile (2) were developed in which DAMN was linked with fluorene and carbazole moiety respectively through imine linkage. ${ }^{34}$ Fluorene and its derivatives are electron rich fluorophore in which two benzene rings connected by a fivemembered ring therefore provide extended $\pi$-conjugated orbitals. The fascinating electronic properties, high quantum yield and high sensitivity make fluorene an effective signalling unit for the development of chemosensors. The synthesized chemosensors (1 \& 2) are $\pi$-conjugated organic molecules with electronic donor $\left(\mathrm{NH}_{2}\right)$ and acceptor $(-\mathrm{CN})$ unit linked by single and double bond leads significant electronics properties due to an intramolecular charge transfer (ICT). The synthesized sensor molecules displayed selective sensing of $\mathrm{F}^{-}$and $\mathrm{CN}^{-}$ions in presence of other anions through colorimetric changes and fluorescence responses (Fig. 3 and 4). The sensor (1) exhibited emission peak at $460 \mathrm{~nm}$ upon excitation at $380 \mathrm{~nm}$. However, presence of $\mathrm{CN}^{-}$ions in solution of sensor (1) shifted the emission peak to $480 \mathrm{~nm}$. The observed $20 \mathrm{~nm}$ red shift was explained by enhancement of intramolecular charge transfer from $-\mathrm{NH}^{-}$group to nitrile group, facilitated by hydrogen bond interaction of $\mathrm{CN}^{-}$ions with amino group (Fig. 3). Other synthesized sensor molecule (2) exhibited peak at $400 \mathrm{~nm}$ in UVvisible spectrum which assigned for the charge transfer from $\mathrm{NH}_{2}$ to $\mathrm{CN}^{-}$of diaminomaleonitrile (DAMN) (Fig. 4). Addition of fluoride ion to sensor (2) solution induced shift of absorption peak from $400 \mathrm{~nm}$ to $470 \mathrm{~nm}$ along with appearance of instance colour of reddish green. The sensing mechanism was further confirmed the by ${ }^{1} \mathrm{H}$ NMR studies and DFT calculations.

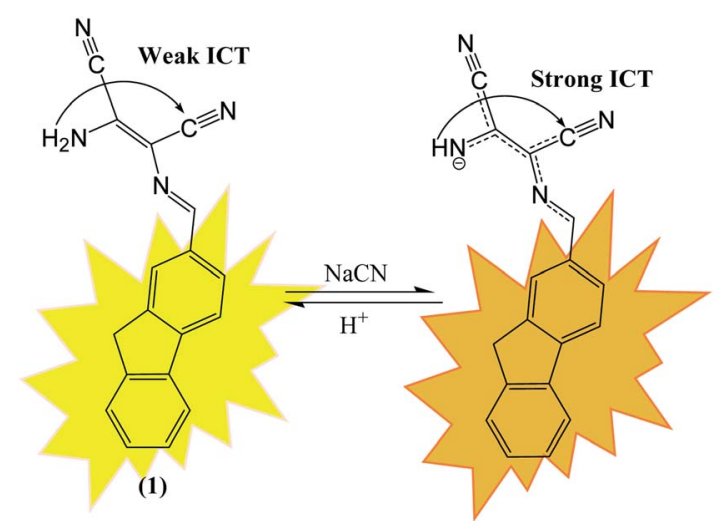

Fig. 3 The mechanism for the fluorescence response of sensor (1) to $\mathrm{CN}^{-}$ion. 


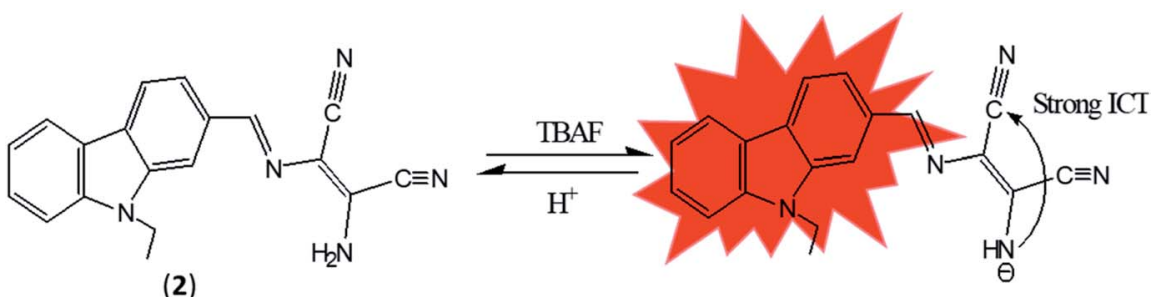

(2)

Fig. 4 The sensing mechanism sensor (2) for $\mathrm{F}^{-}$ion.

In this direction, Son et al. have developed extended $\pi$ conjugated system (3) in which both ends of dioctyl fluorenedibenzene were linked with two DAMN units through imine linkage (Fig. 5). ${ }^{35}$ The incorporation of two DAMN made this sensor (3) very efficient for detection of $\mathrm{CN}^{-}$ion in aqueous medium in nano-molar concentration which is much lower than the concentration level recommended by World Health Organization guidelines. The sensor (3) exhibited intense colour change from yellow to red along with fluorescence turnon response upon interaction with $\mathrm{CN}^{-}$ion. Additionally, it was observed that in presence of $\mathrm{CN}^{-}$ion, absorption peak at $406 \mathrm{~nm}$ in UV-visible spectrum was shifted to $478 \mathrm{~nm}$ with isosbestic point at $446 \mathrm{~nm}$. The shift in absorption maxima was explained by the deprotonation of $\mathrm{NH}_{2}$ of DAMN coupled with intermolecular charge transfer led to enhancement of donor-toacceptor ICT transition (Fig. 5). They also examined the sensitivity of sensor (3) towards other anions such as $\mathrm{H}_{2} \mathrm{PO}_{4}{ }^{-}, \mathrm{NO}_{3}{ }^{-}$, $\mathrm{AcO}^{-}, \mathrm{F}^{-}, \mathrm{Cl}^{-}, \mathrm{Br}^{-}$and $\mathrm{I}^{-}$but none of these ions showed any responses in absorption, emission spectrum and colorimetric sensing.

Another DAMN derived biocompatible duel channel probe (4) was synthesized from hydroxyl benzothiazole moiety and 2,3-diaminomaleonitrile for selective detection of toxic $\mathrm{CN}^{-}$ ions in $50 \%$ aqueous DMF. ${ }^{36}$ The merits of the probe (4) were; (i) reversibility; (ii) non-cytotoxicity; (iii) excellent cell viability; (iv) $0.16 \mu \mathrm{M}$ detection limit and (v) imaging of $\mathrm{CN}^{-}$in live fibroblast L929 cells. The interaction of $\mathrm{CN}^{-}$ion with probe (4) resulted in disappearance of absorption peak at $370 \mathrm{~mm}$ with evolution of $445 \mathrm{~nm}$ peak with isosbestic point at $390 \mathrm{~nm}$ in UV-visible spectrum. Along with this, colorimetric change from yellow to red was observed upon addition of $\mathrm{CN}^{-}$ion into solution of probe (4). These observations were explained by the electronic push-pull effect from amino group of DAMN to nitrile groups resulted from interaction of anion with $\mathrm{N}-\mathrm{H}$ bond which led polarization of $\mathrm{N}-\mathrm{H}$ bond and then deprotonation process. In fluorescence studies, probe (4) exhibited weak emission peak at $517 \mathrm{~nm}$ upon excitation at $450 \mathrm{~nm}$ which was explained by the fact that photo-induced electron transfer process generated from amino group suppressed the emission response. The observed weak emission peak at $517 \mathrm{~nm}$ was significantly intensified in response to $\mathrm{CN}^{-}$ion probably due to the abstraction of proton of amino group by $\mathrm{CN}^{-}$ion which resulted strong intramolecular charge transfer process (ICT) from amine to nitrile units of DAMN. The strong ICT prevent photo-induced electron transfer process resulted in significant fluorescence enhancement (Fig. 6). Additionally, fluorescence turn-on behaviour of probe (4) upon interaction with $\mathrm{CN}^{-}$ion can also supported from suppression of ESIPT process (excited state intramolecular proton transfer) because of deprotonation of benzothiazole-phenol unit.

Indole and its derivative are interesting heterocyclic scaffolds attracted immense interest of medicinal and organic chemists due to its important application in medicinal and biological field. The structure of indole comprises with pyrrole
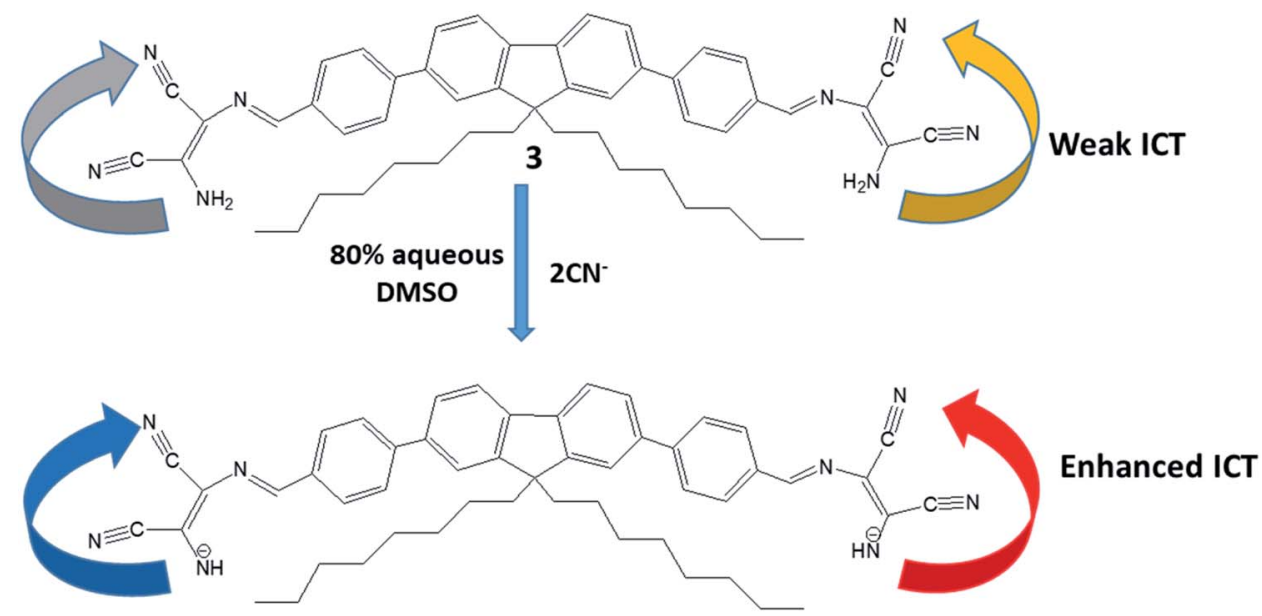

Fig. 5 The mechanism for the fluorescence response of sensor (3) to $\mathrm{CN}^{-}$ion. 

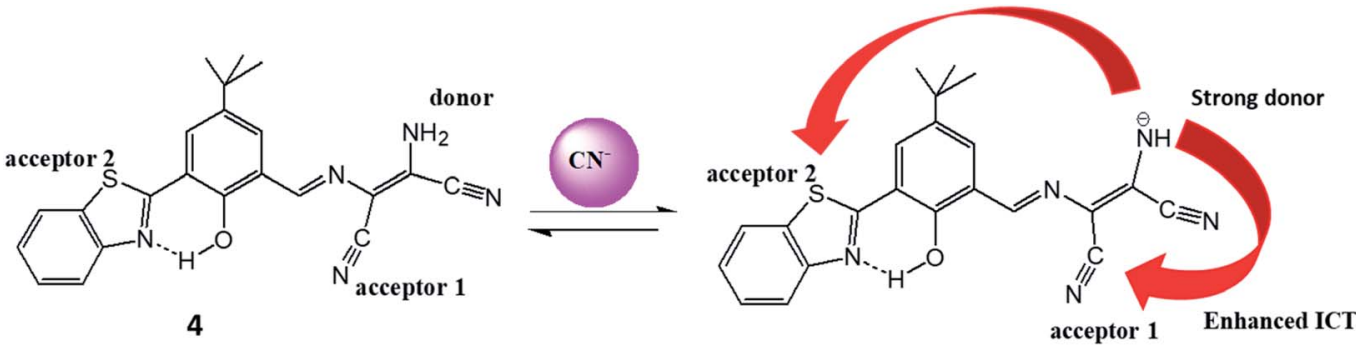

Fig. 6 The mechanism for the fluorescence response of sensor (4) to $\mathrm{CN}^{-}$ion.

and benzene rings makes it attractive fluorophore for designing of sensible sensor molecules. Additionally, the presence of $\mathrm{N}-\mathrm{H}$ group in indole moiety can be utilized for sensing of anions through hydrogen bond interaction. To utilize these properties, a duel channel chemosensor (5) comprising two indole moieties was synthesized from condensation reaction of diaminomaleonitrile with indole-3-carboxaldehyde for sensing of fluoride ion. ${ }^{37}$ Reported sensor 5 selectively sensed fluoride ion without interferences of other anions. The significant changes in emission and absorption spectrum upon addition of fluoride was explained on the basis of hydrogen bond interaction between $\mathrm{F}^{-}$ion and $\mathrm{N}-\mathrm{H}$ group of indole moiety. The sensing studies of chemosensor (5) has been validated by ${ }^{1} \mathrm{H}$ NMR titration and spectrophotometric titrations.

Apart from DAMN based organic molecules, DAMN based metal complexes also showed interesting sensing properties. Two such complexes uranyl- $N, N^{\prime}$-bis(5-tert-butyl-2-hydroxybenzylidene)-1,2dicyano-1,2-ethenediamine (6) and uranyl- $N, N^{\prime}$-bis(3,5-ditertbutyl2-hydroxybenzylidene)-1,2-dicyano-1,2-ethenediamine (7) were developed by Cort and his group by reaction of salycilaldehydes derivatives, 1,2-diaminomaleonitrile and uranyl acetate for selective sensing of halide ion in chloroform and dichloromethane. ${ }^{38}$ Sensor 6 and 7 showed selectivity trends for halide ions in order of $\mathrm{F}^{-}>\mathrm{Cl}^{-}$ $>\mathrm{Br}^{-}$which is in good agreement of hardness of anions. Among $\mathbf{6}$ and 7 , compound 7 showed change in colour upon addition of fluoride and chloride ion but it exhibits fluorescence "turn-on" response only with fluoride ion in both $\mathrm{CH}_{2} \mathrm{Cl}_{2}$ and $\mathrm{CHCl}_{3}$. The weak sensing response of $\mathbf{6}$ towards halide ion was explained from its higher stability of the dimer formation as compare to 7. Further, they calculated distances of $\mathrm{U} \cdots \mathrm{X}\left(\mathrm{X}=\mathrm{F}^{-}, \mathrm{Cl}^{-}, \mathrm{Br}^{-}\right)$from DFT calculation for providing support to metal center and bound halide ions interactions.

\section{DAMN based chemosensors for metal ions}

Metal ions are essential for many environmental, industrial, biological and chemical processes. Some metal ions like $\mathrm{Cu}^{2+}$, $\mathrm{Zn}^{2+}, \mathrm{Fe}^{2+} / \mathrm{Fe}^{3+}, \mathrm{Co}^{2+}, \mathrm{Mn}^{2+}$ etc. are necessary to perform numerous biological functions and enzymatic actions to support life cycles. However high dosages, long-lasting exposure, imbalance in regulations of these ions lead different adverse effect on human health and environment. ${ }^{39}$ For instance, excess accumulation of $\mathrm{Cu}^{2+}$ ion causes kidney damage and Wilson disease, excess intake of $\mathrm{Mn}^{2+}$ lead to manganism and excess $\mathrm{Zn}^{2+}$ intake causes vomiting, headache and nausea. On the other hand, some metal ions like $\mathrm{Hg}^{2+}$, $\mathrm{Cd}^{2+}, \mathrm{Pb}^{2+}, \mathrm{Cr}^{3+}$ and $\mathrm{As}^{3+}$ are toxic in nature without any beneficial effects on human health. Literature revealed that accumulation of these ions lead serious illnesses like damages of central nervous system, brain dysfunction, eyes, lungs, mental retardation and many more. The direct or indirect involvement of metal ions in serious diseases increases demands of effective organic molecules based sensing systems for quantitative and qualitative sensing of metal ions at low detection level therefore various research groups are involved in developing such systems for easy and selective detection of metal ions. DAMN derived sensor molecules for metal ions have been proven to be an attractive choice due to inimitable structural features which arise fascinating electronic properties.

To develop sensor molecules for metal ions, aza-crown ether moieties have been introduced into DAMN scaffold, as aza-crown ethers have excellent capability for binding to specific metal ions with stable complexation because of the nitrogen/oxygen are situated at interior of the ring to coordinate with target cation. The selectivity of these molecules depends on size of cavity as well as number of oxygen and
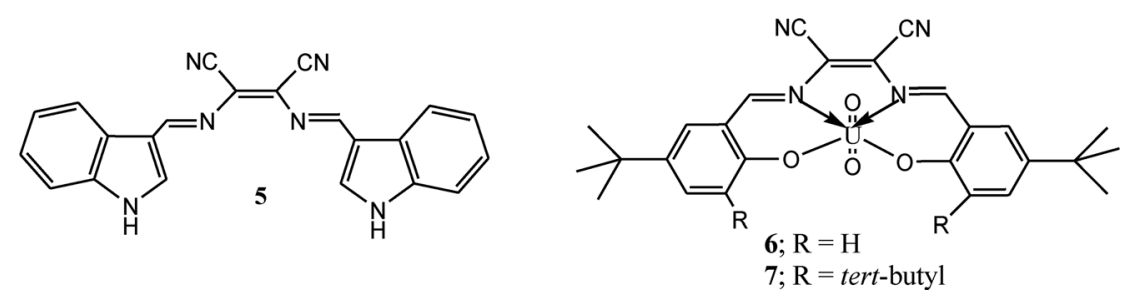
nitrogen atoms. Thus, Zhou and his group introduced azacrown ether moiety into diaminomaleonitrile through condensation reaction between diaminomaleonitrile with 4(1,4,7,10-tetraoxa-13-aza cyclopentadecyl)benzaldehyde or 4$(1,4,7,10,13$-pentaoxa-16-aza cycloctadecyl)benzaldehyde in benzene with aim to combine two binding sites in single sensor molecules. ${ }^{40}$ The sensor molecules (8 \& 9) having different cavity size of aza-crown ether moieties were examined for sensing of metal ions. It was found that sensor 8 having smaller cavity size as compare to 9 showed different colorimetric responses for $\mathrm{Hg}^{2+}$ and $\mathrm{Cu}^{2+}$ ions. For example, $8-\mathrm{Hg}^{2+}$ turned to pale yellow whereas $8-\mathrm{Cu}^{2+}$ turned to colorless within a wide $\mathrm{pH}$ range of 5.5-10.5. In UV-visible spectrum, sensor 8 showed absorption peak at $420 \mathrm{~nm}$ which was decreased and appearance of a peak at $336 \mathrm{~nm}$ with isosbestic point at $366 \mathrm{~nm}$ upon stepwise addition of $\mathrm{Cu}^{2+}$ ion. The mole fraction at 0.5 in Job's plot revealed $1: 1$ binding stoichiometry between $\mathrm{Cu}^{2+}$ and 8 and stability constant was found to be $1.04 \times 10^{4} \mathrm{M}^{-1}$. In case of sensor 9 with larger cavity as compare to $\mathbf{8}$ showed different sensing behavior for $\mathrm{Cu}^{2+}$ ion. They found that upon addition of $\mathrm{Cu}^{2+}$ to $\mathbf{9}$, absorptions peaks centered at 300 and $420 \mathrm{~nm}$ were decreased with isosbestic points at $316 \mathrm{~nm}$ and $373 \mathrm{~nm}$ while addition of more than 0.8 equivalents of $\mathrm{Cu}^{2+}$ ion, new absorption peak at $260 \mathrm{~nm}$ appeared with new isosbestic point at $297 \mathrm{~nm}$. It was also observed that sensor 9 showed much lower detection limit for $\mathrm{Cu}^{2+}$ ion in comparison of $\mathbf{8}$. These differences in selectivity for $\mathrm{Cu}^{2+}$ ion was observed due to consequences of difference in cavity size of aza-crown ethers. The sensitivity of $\mathbf{8}$ was explained by the fact that $\mathrm{Cu}^{2+}$ ion coordination with the donor nitrogen atom of aniline group of DAMN while larger cavity of aza-crown ether and DAMN in 9 have competition in sensing of $\mathrm{Cu}^{2+}$ ion which was further supported by theoretical calculations.
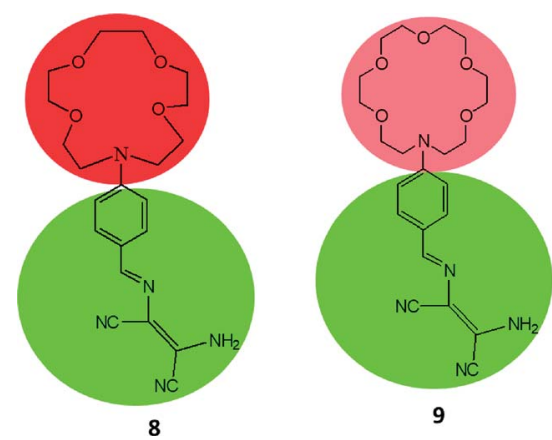

Most of chemosensor molecules showed fluorescence turnoff responses for sensing of $\mathrm{Cu}^{2+}$ ion due to the paramagnetic nature of $\mathrm{Cu}^{2+}$ ion which may sometime reduce the sensitivity and selectivity of sensor molecules. In comparison to this, ratiometric and turn-on fluorescent sensors are much better options for sensing of $\mathrm{Cu}^{2+}$ ion due to better sensitivity and selectivity. In this context, DAMN based turn-on fluorescent sensor for $\mathrm{Cu}^{2+}$ ion using naphthalimide moiety was reported. ${ }^{\mathbf{4 1}}$ Naphthalimide moiety is exceptional fluorogenic in nature widely used in designing of chemosensor molecules. The emission and absorption properties of naphthalimide derivatives largely depend upon substituents on naphthalimide skeleton and can be fine-tuned as per need. The reported DAMN conjugated naphthalimide sensor (10) showed two different emission channel upon addition of different concentrations of $\mathrm{Cu}^{2+}$ ions (Fig. 7). For instance, addition of less than 1.0 equivalent of $\mathrm{Cu}^{2+}$ ion, both absorbances at 325 and $405 \mathrm{~nm}$ decreased while addition of $\mathrm{Cu}^{2+}$ ion beyond 1.0 eq. induced increase of the absorption peak at $325 \mathrm{~nm}$ and a monotonic decrease at $405 \mathrm{~nm}$. In fluorescence titration experiments, lower than 1.0 equivalent of $\mathrm{Cu}^{2+}$ ion, the intensity of emission peak at $522 \mathrm{~nm}$ was increased while further addition of $\mathrm{Cu}^{2+}$ ion, peak at $522 \mathrm{~nm}$ disappeared and a new emission peak gradually appeared at $425 \mathrm{~nm}$. In the sensing process the first equivalent of $\mathrm{Cu}^{2+}$ ion coordinate with nitrogen atoms of imine and amine group and block the photo-induced electron transfer which results in significant fluorescence enhancement at $522 \mathrm{~nm}$. Further, binding of second equivalent of $\mathrm{Cu}^{2+}$ ion with nitrile group of DAMN enhance the electron-withdrawing ability of imine group which results shift of emission peak from 522 to $425 \mathrm{~nm}$. These observations were obtained only in acetonitrile solvent system whereas in other solvents like DMF, THF, water and DMSO only fluorescence enhancement at $522 \mathrm{~nm}$ was observed which clearly indicated that binding ability of nitrile group to $\mathrm{Cu}^{2+}$ was weak in nature and was replaced by the solvents having strong binding ability. In the continuation of this work, an interesting DAMN based fluorescent turn-on sensor for $\mathrm{Cu}^{2+}$ ion using indoline moiety (11) was reported with excellent detection limit of $6.18 \times 10^{-8} \mathrm{~mol} \mathrm{~L}^{-1} \cdot{ }^{42}$ The synthesized sensor 11 displayed large Stokes shift of $146 \mathrm{~nm}$ which can reduce the impact of automatic fluorescence and selfextinguishing thus suitable for wide applications. The fluorescence turn-on response of $\mathbf{1 1}$ was described by prevention of the photo-induced electron transfer (PET) process from indole moiety (donor) to DAMN unit (receptor).

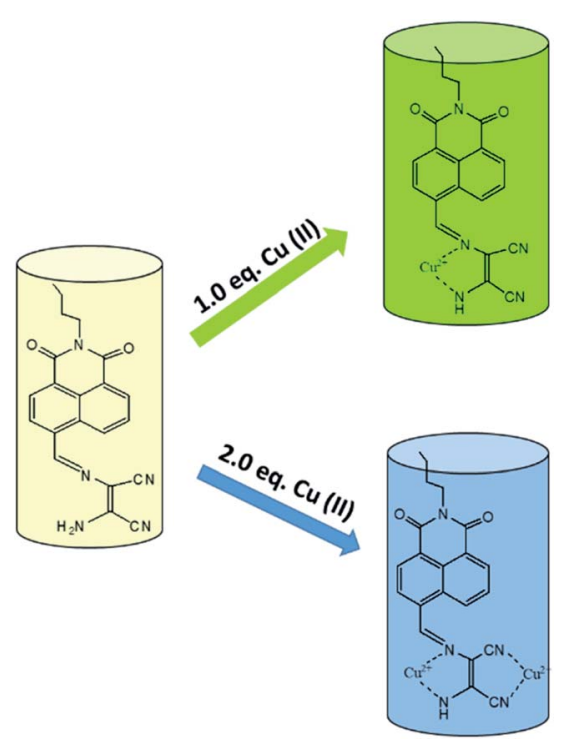

Fig. 7 Colorimetric responses sensor (10) with different equivalent of to $\mathrm{Cu}^{2+}$ ion. 
<smiles>CN1/C(=C/C=N/C(C#N)=C(/N)C#N)C(C)(C)c2ccccc21</smiles>

To improve the sensitivity of sensor, 3-hydroxynaphthalimide was used to construct effective naphthalimide based sensor molecules in which oxygen atom of hydroxyl group also participate in binding process. ${ }^{42}$ The resulting sensor (12) was examined for sensing of different metal ions and result showed selective colorimetric response from yellow to pink only for $\mathrm{Cu}^{2+}$ ion with detection limit of $1.6 \mu \mathrm{M}$. For instance, 12 showed strong absorbance at $457 \mathrm{~nm}$ which was decreased on addition of $\mathrm{Cu}^{2+}$ ion whereas new peak at $565 \mathrm{~nm}$ was evolved and enhancement of absorbance at $565 \mathrm{~nm}$ was more than 50 fold. The selectivity of the receptor was also checked by mixing other interfering metal ions with $\mathrm{Cu}^{2+}$ ion, even in the complex mixture sensor 12 selectively detected copper ion. The nature of the interaction between the $\mathbf{1 2}$ and $\mathrm{Cu}^{2+}$ ion was established through various analysis. The Job's plot indicated the formation $1: 1$ complex and DynaFit curve fitting program also indicated formation of $1: 1$ complex with association constant $\left(K_{\text {asso }}\right) 5.9$ $\times 10^{4} \mathbf{M}^{-1}$. An $m / z$ peak at 449.3 in mass spectra indicated formation of a 12- $\mathrm{Cu}^{2+}$ complex in which $\mathrm{Cu}^{2+}$ ion binded with oxygen atom of hydroxyl group and nitrogen atom of amino group (Fig. 8). The use of the receptor in practical application was demonstrated on simulated semiconductor wastewater by extracting the $\mathrm{Cu}^{2+}$ ion in DMSO-ethyl acetate (containing the receptor) medium at $4.8 \mathrm{pH}$. After extraction the image of the ethyl acetate phase was captured using a smartphone and the image was analysed using RGB Grabber (Shunamicode) application in smartphone. A calibration curve made by red/green ratio as function of $\mathrm{Cu}^{2+}$ ion gave satisfactory $\mathrm{Cu}^{2+}$ concentration result in simulated semiconductor wastewater.

In another report benzimidazole derivative was coupled with two molecules of DAMN as optical properties of benzimidazole is highly sensitives towards metal ions interaction even in micro to nano level concentration. ${ }^{\mathbf{4 3}}$ Sensor $\mathbf{1 3}$ demonstrated selective turn on fluorescent sensing behaviour for $\mathrm{Cu}^{2+}$ ion with $0.49 \mu \mathrm{M}$ detection limit which was much lower concentration than permissible limit of $\mathrm{Cu}^{2+}$ ion in drinking water allowed by United States Environmental Protection Agency. ${ }^{\mathbf{4 4}}$ The emission spectrum of 13 showed weak emission peak at $405 \mathrm{~nm}$ which enhanced to 155-fold with large Stokes shift of $60 \mathrm{~nm}$ on

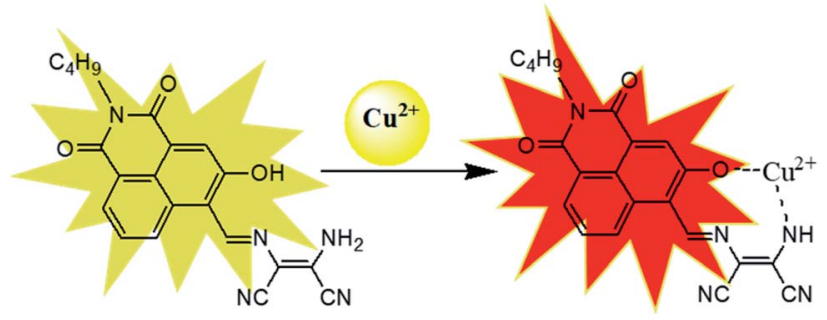

12

Fig. 8 The sensing mechanism of sensor (12) for $\mathrm{Cu}^{2+}$ ion. addition of $\mathrm{Cu}^{2+}$ ion. The most important aspect of sensor $\mathbf{1 3}$ is that it can selectively detect $\mathrm{Cu}^{2+}$ ion in presence other interfering ions in aqueous medium in wide $\mathrm{pH}$ range. The binding mode of sensor with $\mathrm{Cu}^{2+}$ ion was determined using Job's plot, mass-spectrometric methods as well as DFT calculation. All these methods indicated $1: 2$ stoichiometry ratio of $13-\mathrm{Cu}^{2+}$ complex (Fig. 9). The $\mathrm{m} / \mathrm{z}$ peak at 752.5849 in mass spectrometric analysis further supported proposed 1 : $213-\mathrm{Cu}^{2+}$ ion complex. DFT analysis showed HOMO $(-6.54 \mathrm{eV})$ and LUMO $(-3.01 \mathrm{eV})$ band gap as $3.53 \mathrm{eV}$, whereas complexation with $\mathrm{Cu}^{2+}$ ion reduced the band gap to $3.24 \mathrm{eV}$. The fluorescence images of cell (HepG2) was carried out in presence of the 13, indicated the permeability and detection ability of the sensor in live cells.

Coumarin derivatives have high fluorescence quantum yield, large stoke shift and high photo-stability thus extensively utilized in designing of fluorescent sensor molecules. A coumarin-DAMN based fluorescent sensor with longer emission wave length was developed in which 7-diethylamino group (electron donor) and DAMN (strong electron acceptor) were introduced into coumarin scaffold to generate an extensive donor-acceptor system which enhanced ICT process. $^{45}$ Although, synthesized sensor (14) exhibited weak fluorescence due to the quenching effect of nitrile group as well as its flexible structure, the intensity of emission peak at $620 \mathrm{~nm}$ was significantly increased up to 35-fold upon interaction with $\mathrm{Zn}^{2+}$ ion along with blue shift of $50 \mathrm{~nm}$. The enhancement of fluorescence intensity was observed due to reduced ICT process and inhibition of conformational change upon combination with $\mathrm{Zn}^{2+}$ ion. The Job's plot revealed the $1: 1$ binding between 14 and $\mathrm{Zn}^{2+}$ ion which was supported by mass spectrometry. In addition, sensor (14) was used for $\mathrm{Zn}^{2+}$ ion imaging in HepG2 cells over $\mathrm{Cd}^{2+}$ ion which usually responses together with $\mathrm{Zn}^{2+}$ ion.<smiles>CCN(CC)c1ccc2cc(/C=N/C(C#N)=C(/C#N)NC(=O)c3ccccn3)c(=O)oc2c1</smiles>

In continuation of our research efforts on developing sensor molecules, ${ }^{\mathbf{4 6 - 5 1}}$ we synthesized hybrid chemosensors by combining diaminomaleonitrile, 4-formyl-1-substituted phenylpyrazole-3-carboxylate and 2-hydroxy-1-naphthaldehyde molecules. ${ }^{52}$ These three moieties were joined together by imine linkages and were capable of sensing $\mathrm{Mn}^{2+}$ and $\mathrm{Zn}^{2+}$ ion in complex mixture through colorimetric and fluorometric response. On addition $\mathrm{Mn}^{2+}$ and $\mathrm{Zn}^{2+}$ salt solutions the pale yellow coloured solution of the sensor (15-17) was immediately changed to dark brown-red and bright yellow colour respectively. The evaluation of interference by different metal ions like $\mathrm{Al}^{3+}, \mathrm{Cr}^{3+}, \mathrm{Cu}^{2+}, \mathrm{Fe}^{3+}, \mathrm{Hg}^{2+}, \mathrm{Co}^{2+}, \mathrm{Pb}^{2+}, \mathrm{Cd}^{2+}$ and $\mathrm{Ni}^{2+}$ indicated the sensor can selectively and efficiently detect $\mathrm{Mn}^{2+}$ and $\mathrm{Zn}^{2+}$ ions in mixture. The immediate colorimetric response made the molecule for possible colorimetric probe for $\mathrm{Mn}^{2+}$ or $\mathrm{Zn}^{2+}$ ions. 


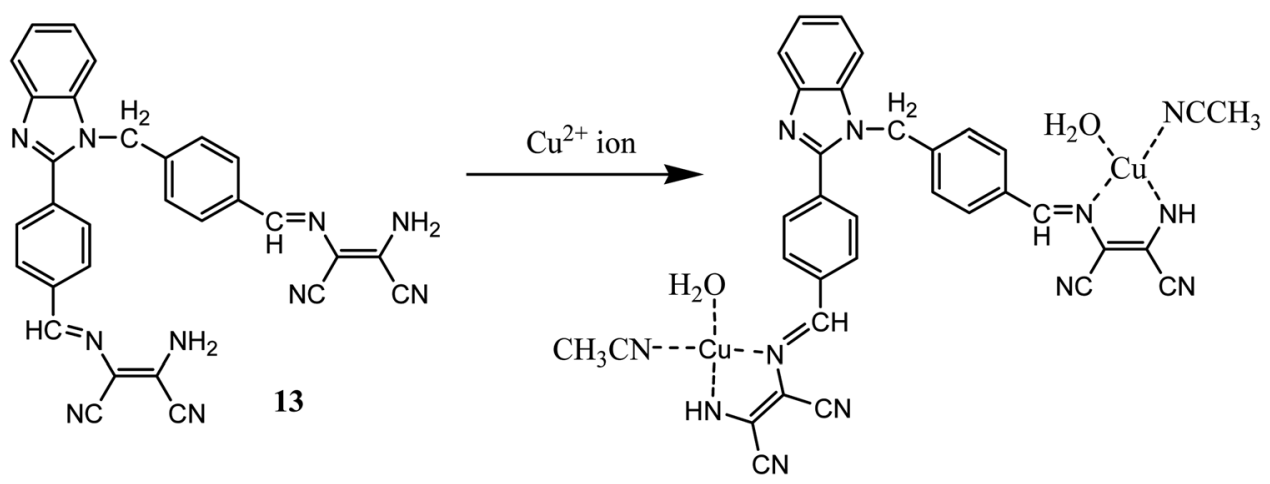

Fig. 9 The sensing mechanism of sensor (13) for $\mathrm{Cu}^{2+}$ ion.

The UV-vis spectroscopic study of the probe molecule showed three absorptions peaks at 328, 406 and $426 \mathrm{~nm}$ with highest absorbance $\left(\lambda_{\max }\right)$ at $406 \mathrm{~nm}$. On gradual addition of $\mathrm{Mn}^{2+}$ ion solution to probe molecule the $406 \mathrm{~nm}$ peak was completely disappeared and evolution of a new peak at $576 \mathrm{~nm}$ was observed. The evolution of new peak was complete with addition of 1.0 equivalent $\mathrm{Mn}^{2+}$ ion. Whereas the gradual addition of $\mathrm{Zn}^{2+}$ ion solution to probe solution resulted in formation of a new peak at $462 \mathrm{~nm}$ and the formation was complete with addition of 2 equivalents of $\mathrm{Zn}^{2+}$ ion. The Job's method and Benesi-Hildebrand plots indicated the $1: 1$ and $1: 2$ binding modes for $\mathrm{Mn}^{2+}$ and $\mathrm{Zn}^{2+}$ respectively. The binding constants for $\mathrm{Mn}^{2+}$ and $\mathrm{Zn}^{2+}$ were found to be $1.22 \times 10^{4} \mathrm{M}^{-1}$ and $3.31 \times$ $10^{8} \mathrm{M}^{-2}$ respectively. The practical applicability of the sensor was tested on tap water samples spiked with standard $\mathrm{Zn}^{2+}$ and $\mathrm{Mn}^{2+}$ ions and the results clearly indicated that the sensor can detect the presence of these ions even from aqueous medium. The fluorescent investigation on the sensor showed an emission peak at $507 \mathrm{~nm}$ upon excitation at $406 \mathrm{~nm}$ and the emission peak intensity decreased by $90 \%$ with addition of $\mathrm{Mn}^{2+}$ ion whereas the intensity of the $507 \mathrm{~nm}$ peak increased by $50 \%$ on addition of $\mathrm{Zn}^{2+}$ ion. The quenching of fluorescent intensity is due to binding of $\mathrm{Mn}^{2+}$ ion with the naphthalenic $\mathrm{OH}$ group and the imine nitrogen moiety, which causes internal charge transfer (ICT). The Stern-Volmer equation showed linear relationship with the quencher $\left(\mathrm{Mn}^{2+}\right.$ ion) concentration, indicating quenching by the $\mathrm{Mn}^{2+}$ ion only. All these studies indicated potential application for detection for detecting $\mathrm{Zn}^{2+}$ and $\mathrm{Mn}^{2+}$ ions in water samples and which can become alternative to expensive techniques like AAS.<smiles>N#C/C(N)=C(\C#N)N=Cc1cn(I)nc1C(=O)N/N=C/c1c(O)ccc2ccccc12</smiles>

15; $\mathrm{R}=$ Phenyl 16; $\mathrm{R}=4-\mathrm{CH}_{3}-$ Phenyl 17; $\mathrm{R}=4-\mathrm{NO}_{2}$-Phenyl

The existence, location and concentration of $\mathrm{Fe}^{3+}$ ions are extremely vital for execution of numerous biological functions in living organism whereas excess and deficiency lead various biological disorders in human body. In view of the paradox of
$\mathrm{Fe}^{3+}$ ion, carbazole-diaminomaleonitrile derived fluorescence turn-off sensor (18) was developed for $\mathrm{Fe}^{3+}$ ion in which carbazole moiety was used a signalling unit. ${ }^{53} \mathrm{~A}$ strong fluorescence emission peak was appeared between $380-420 \mathrm{~nm}$ under excitation at $280 \mathrm{~nm}$ due to highly conjugated structure of sensor in which two carbazole unit connected on both end of DAMN through imine bond. The addition of $\mathrm{Fe}^{3+}$ ion in the solution of sensor induced significant fluorescence quenching while other metal ions like $\mathrm{K}^{+}, \mathrm{Mn}^{2+}, \mathrm{Ag}^{+}, \mathrm{Co}^{2+}, \mathrm{Zn}^{2+}, \mathrm{Ni}^{2+}, \mathrm{Pb}^{2+}, \mathrm{Cd}^{2+}, \mathrm{Mg}^{2+}$, $\mathrm{Sr}^{2+}, \mathrm{Ca}^{2+}, \mathrm{Hg}^{2+}, \mathrm{Ba}^{2+}, \mathrm{Cu}^{2+}, \mathrm{Fe}^{2+}, \mathrm{Cr}^{3+}$ and $\mathrm{Al}^{3+}$ did not influence the emission intensity of sensor. The nitrogen atoms of $\mathbf{1 8}$ were used for coordinating $\mathrm{Fe}^{3+}$ ion which induced internal charge transfer process from nitrogen of carbazole unit to $\mathrm{Fe}^{3+}$ ion causes significant fluorescence quenching (Fig. 10). Additionally, 18 showed fast response time with detection limit of $3.75 \times$ $10^{-8} \mathrm{M}$ for $\mathrm{Fe}^{3+}$ ion which make it useful for real time applications.

Mercury exists in nature mainly in organic, inorganic and elemental forms. All these forms have strong affinity toward carboxyl, thiol and phosphate functional groups present in human body which causes serious toxic effects. DAMN moiety was also used in development of sensor molecules for sensing of mercury. In this context, a highly efficient reversible chromofluorescent molecular probe (19) was synthesized by conjugating triphenyl amine and DAMN where triphenyl amine act as signalling unit and DAMN act as a binding unit. ${ }^{54}$ The synthesized receptors (19) exhibited absorption peak centred at $447 \mathrm{~nm}$ which shifted to $508 \mathrm{~nm}$ upon addition of $\mathrm{Hg}^{2+}$ with appearance of instant orange colour from light yellow in acetonitrile : water $(1: 1)$ solution. The observed red shift $(60 \mathrm{~nm})$ in the absorption spectra is probably due to the enhancement of intermolecular charge transfer after complexation of the $\mathrm{Hg}^{2+}$ ion with receptor. In addition to this Job's continuous variation method indicated $1: 2$ binding stoichiometry between sensor (19) and $\mathrm{Hg}^{2+}$ ions (Fig. 11). The detection limit was found to be $5.2 \mu \mathrm{M}$ at neutral $\mathrm{pH}$ in $50 \%$ aqueous acetonitrile solution.

Sekar et al. fabricated colorimetric test strips based on DAMN derived sensor (20) for convenient and efficient sensing of $\mathrm{Hg}^{2+}$ ions. These test strips showed visible color changes for sensing of $\mathrm{Hg}^{2+}$ ion in acetonitrile. The chemosensor (20) used in test strips was synthesized by the combination of diaminomaleonitrile and 3-hydroxy-1,4-dioxo-1,4- 


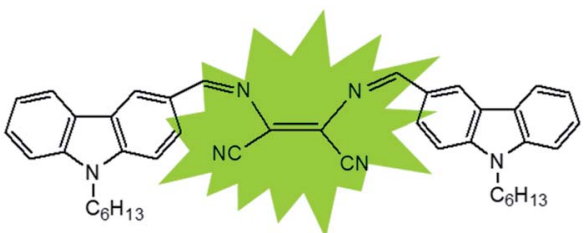

18

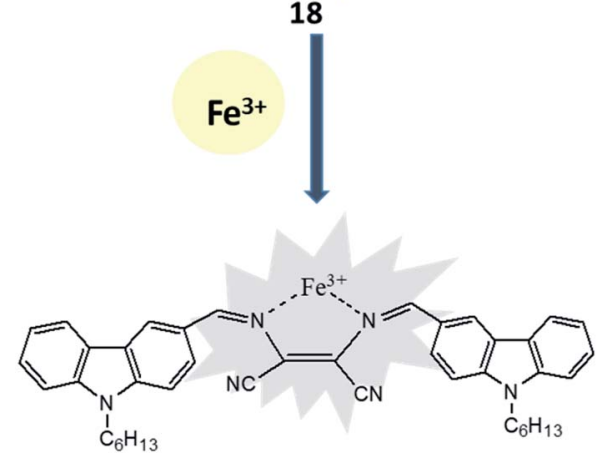

Fig. 10 The sensing mechanism for sensor (18) or $\mathrm{Fe}^{3+}$ ion.

dihydronaphthalene-2-carbaldehyde. ${ }^{55}$ The colorimetric sensing abilities of sensor (20) for $\mathrm{Hg}^{2+}$ ion was again evaluated by UV-visible spectroscopy. It was observed that absorption bands of 20 at $335 \mathrm{~nm}$ and $481 \mathrm{~nm}$ were disappeared and new absorption bands at $421 \mathrm{~nm}$ and $595 \mathrm{~nm}$ were appeared on addition of $\mathrm{Hg}^{2+}$ ion. It was found that absorption peak at $595 \mathrm{~nm}$ reached its saturation point upon addition of 1.0 equivalent of $\mathrm{Hg}^{2+}$ ion indicating the formation of $1: 1$ binding stoichiometry. The Job's plot, ESI-mass spectrometry analysis ${ }^{1} \mathrm{H}$ NMR titration and DFT calculations further confirmed the $1: 1$ binding mode [Fig. 12].

Huo et al. reported five diaminomaleonitrile based Schiff base compounds (21-25). These Schiff bases were prepared by condensation of substituted-benzaldehyde (electron donor) and diaminomaleonitrile (electron acceptor). These compounds showed selective and efficient sensing of $\mathrm{Hg}^{2+}$ ion in ethanolic aqueous medium with micro molar detection limit. ${ }^{56}$ These sensor molecules exhibited visual colour changes upon interaction with $\mathrm{Hg}^{2+}$ ion over other tested metal ions $\left(\mathrm{K}^{+}, \mathrm{Ca}^{2+}, \mathrm{Ba}^{2+}\right.$, $\mathrm{Co}^{2+}, \mathrm{Cd}^{2+}, \mathrm{Mg}^{2+}, \mathrm{Ag}^{+}, \mathrm{Na}^{+}, \mathrm{Fe}^{3+}, \mathrm{Cu}^{2+}, \mathrm{Ni}^{2+}, \mathrm{Al}^{3+}, \mathrm{Zn}^{2+}, \mathrm{Cr}^{3+}$ and $\mathrm{Pd}^{2+}$ ) in aqueous medium. For example, addition of 1.0 equivalent of $\mathrm{Hg}^{2+}$ ion changed the colourless solutions of 21-24 to yellow whereas pale yellow colour solution of 25 changed to orange red.

The sensor molecules (21-25) showed maximum absorbance peaks $\left(\lambda_{\max }\right)$ centred at $362,364,365,377$ and $421 \mathrm{~nm}$ respectively. Addition of $\mathrm{Hg}^{2+}$ ion to solution of 24 caused a $28 \mathrm{~nm}$ redshift (from 377 to $405 \mathrm{~nm}$ ) and almost similar shifts in absorption peaks were observed with other sensor molecules (21-23 \& 25). The binding mode of the sensors and $\mathrm{Hg}^{2+}$ ion was determined by Jos's plot method, indicated $2: 1$ binding stoichiometry which were confirmed by Benesi-Hildebrand equations (Fig. 13). The binding constants $\left(K_{\text {asso }}\right)$ was found in the range of $10^{2}$ to $10^{3} \mathrm{M}^{-1}$. Crystals of sensor molecules (23 and 24) and its complex with $\mathrm{Hg}^{2+}$ were grown and single crystal X-ray diffraction study revealed that $\mathbf{2 3}$ crystallized in the monoclinic crystal system with $P 2{ }_{1} / c$ space group and the $24-\mathrm{Hg}^{2+}$ complex crystallized in the monoclinic crystal system with $C_{2} / c$ space group.

Salen type ligands and its metal complexes have attracted immense attention in various fields like organic light-emitting diodes, catalysts, magnetic materials, supramolecular materials and cell imaging. These ligands and their complexes are easy to synthesis, reasonably stable and rich in photophysical properties. Furthermore, luminescent Salen ligands having $\pi$ conjugated tetradentate $\left[\mathrm{O}^{\wedge} \mathrm{N}^{\wedge} \mathrm{N}^{\wedge} \mathrm{O}\right]$ chelating system are capable to coordinate with different metal ions, thus widely used in detection of wide-range of metal ions. Xiang group has recently prepared two Salen type ligands (26 and 27) by condensation reaction of diaminomaleonitrile and 4-(diethylamino)salicylaldehyde. ${ }^{57}$ Due to presence of diaminomaleonitrile moiety, it was possible to synthesize both cis and trans isomers. These isomers have $\mathrm{pH}$ sensitive groups such as hydroxyl, dimethylamine and $-\mathrm{C}=\mathrm{N}$ and ease of acid catalysed hydrolysis of these two ligands were exploited to get wide range $\mathrm{pH}$ probe using these compounds. These Salen $\mathrm{pH}$ probes were able to detect $\mathrm{pH}$ ranging from 1-12 in both colorimetric and fluorometric modes. It is important to note that addition of $\mathrm{OH}^{-}$ions (higher $\mathrm{pH}$ ) the phenolic $-\mathrm{OH}$ group gets deprotonated and colour of the probe changes from pink to blue whereas addition of $\mathrm{H}^{+}$ions (lower $\mathrm{pH}$ ), colour of the probe solution changes from pink to purple due to protonation of imine nitrogen. Further addition of acid, probe gets hydrolysed to constituent diaminomaleonitrile and 4-(diethylamino)<smiles></smiles>

Fig. 11 The $1: 2$ binding complexation between sensor (19) and $\mathrm{Hg}^{2+}$ ions. 


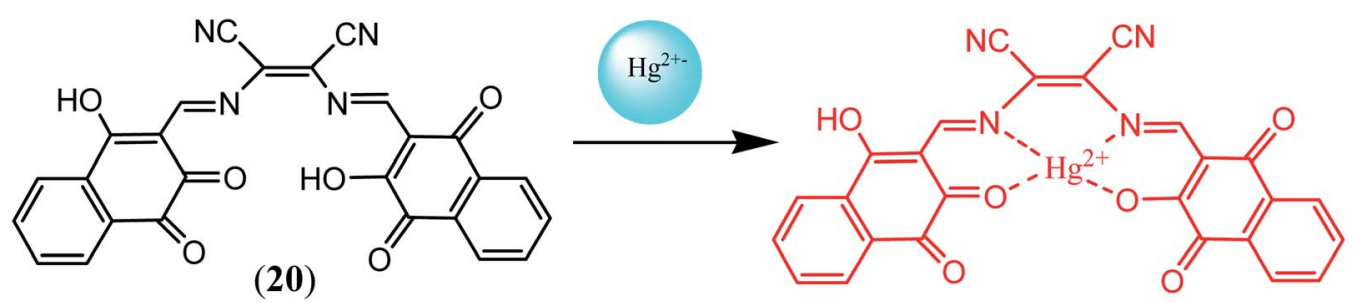

Fig. 12 The binding mechanism between sensor (20) and $\mathrm{Hg}^{2+}$ ions.<smiles>[R]C=N/C(C)=C(/N)C#N</smiles><smiles></smiles>

22; R2=<smiles>Cc1c(F)c(F)c(F)c(F)c1F</smiles>

23; R3=<smiles>Cc1ccc(C(C)(C)C)cc1</smiles>

24; $\mathrm{R} 4=$<smiles>COCc1ccccc1OC</smiles><smiles>Cc1cc2ccc3cccc4ccc(c1)c2c34</smiles>

Fig. 13 General 2 : 1 binding mode between sensor (21-25) and $\mathrm{Hg}^{2+}$ ions.

salicylaldehyde with disappearance of colour. All these protonated and deprotonated species were confirmed by ${ }^{1} \mathrm{H}$ NMR measurements in which $\mathrm{OH} \operatorname{signal}(\delta=11.71 \mathrm{ppm})$ disappeared upon addition of base and $\mathrm{N}=\mathrm{CH}$ signal shifted from $\delta=$ $8.43 \mathrm{ppm}$ to 9.60 with addition of acid.
Among these two isomers cis isomer can act as tetradentate ligand whereas the trans form can act as bidentate ligand. It was observed that cis isomer can bind with various metal ions like $\mathrm{Cu}^{2+}, \mathrm{Co}^{2+}$ and $\mathrm{Fe}^{3+}$ and noticeable change in colour was observed by naked eye and fluorescence quenching response. In contrast to the cis isomer the trans isomer was able to detect $\mathrm{Cu}^{2+}$ ion selectively in ppb level by quenching the fluorescent intensity at $610 \mathrm{~nm}$ by $96 \%$ upon addition of 1.0 equivalent of $\mathrm{Cu}^{2+}$ ion and $100 \%$ quenching upon addition of 4.0 equivalents of $\mathrm{Cu}^{2+}$ ions. The investigation of $\mathrm{Cu}^{2+}$ ion detection mechanism indicated formation of a $1: 1$ trans ligand- $\mathrm{Cu}^{2+}$ complex, which then hydrolysed to diaminomaleonitrile and 4-(diethylamino)salicylaldehyde. The practical applicability of the trans isomer was checked by making the paper strip with the ligand and the dipping the strips in aqueous $\mathrm{Cu}^{2+}$ ion solution, acid and base solution. The obvious colour changes were observed as in solution.

\section{DAMN based chemosensors for multiple ions}

More recently attention has been focused on the designing of multifunctional sensor molecules in which two or more binding sites are incorporated within a single framework that features simultaneous binding of multiple guest species. These multifunctional receptors are of inherent interest because of their potential applications in environmental protection, biological processes and industry. ${ }^{58}$ Several multifunctional sensor molecules using diaminomaleonitrile (DAMN) have been reported for sensing of multiple guest species. For instance, Kim and his group designed diaminomaleonitrile (DAMN) based colorimetric receptor for sensing of $\mathrm{CN}^{-}$and $\mathrm{Cu}^{2+}$ ions. ${ }^{59}$ Receptor 28 was synthesized by<smiles>CCN(CC)c1ccc(/C=N/C(C#N)=C(C#N)/N=C/c2ccc(N(CC)CC)cc2O)c(O)c1</smiles> 
reaction of 2-amino-3-(((E)-(8-hydroxy-2,3,6,7-tetrahydro-1 $H, 5 H$-pyrido[3,2,1-ij]quinolin-9-yl)methylene)amino)maleonitrile with salicylaldehyde. In initial studies, it was observed that violet color solution of 28 changed to pale yellow color upon addition of $\mathrm{CN}^{-}$ ions while interfering ions like $\mathrm{F}^{-}, \mathrm{AcO}^{-}, \mathrm{Cl}^{-}, \mathrm{Br}^{-}, \mathrm{H}_{2} \mathrm{PO}_{4}{ }^{-}, \mathrm{N}_{3}^{-}$ and $\mathrm{SCN}^{-}$were remained unresponsive in $\mathrm{DMSO} /$ bis-tris buffer $(9: 1, \mathrm{v} / \mathrm{v})$. UV-visible studies revealed that incremental addition of $\mathrm{CN}^{-}$ion to 28 solution resulted disappearance of absorption peak at $560 \mathrm{~nm}$ with appearance of new peak at $445 \mathrm{~nm}$ along with isosbestic point at $375 \mathrm{~nm}$. These observations indicated that addition of $\mathrm{CN}^{-}$ion reduced the intramolecular charge transfer efficiency which lead to blue shift in absorption peak from 560 to $445 \mathrm{~nm}$. Interestingly, ${ }^{1} \mathrm{H}$ NMR studies showed that after addition $\mathrm{CN}^{-}$ion, the $\mathrm{CH}=\mathrm{N}$ proton signal shifted from $8.9 \mathrm{ppm}$ to $5.7 \mathrm{ppm}$ which indicated that $\mathrm{CN}^{-}$ion acted as a nucleophile. In addition to this, cation sensing efficacy of 28 was examined by using nitrate salts of different metal ions in $\mathrm{CH}_{3} \mathrm{CN}$. It was found that 28 showed instant color change from violet to pale yellow and distinct spectral change upon interaction with only $\mathrm{Cu}^{2+}$ ion. These changes were explained by the decrease in the push-pull effect of the ICT transition induced by interaction of $\mathrm{Cu}^{2+}$ ion to the imine groups and $\mathrm{OH}$ of receptor 28 (Fig. 14).

In an another report, a multifunctional chemosensor based on julolidine and diaminomaleonitrile moieties was designed for detection of both $\mathrm{Cu}^{2+}$ and $\mathrm{F}^{-}$ion. ${ }^{60}$ The chemosensor (29) displayed absorption peak at $450 \mathrm{~nm}$ which was gradually decreased and simultaneously new peak at $375 \mathrm{~nm}$ was appeared with change in color from yellow to colorless on addition of $\mathrm{Cu}^{2+}$ ions. The sensing mechanism revealed the involvement of $\mathrm{OH}$ and $\mathrm{NH}_{2}$ groups of the receptor in $\mathrm{Cu}^{2+}$ ion binding led decrease intermolecular charge transfer transition (Fig. 15). It was found that sensor (29) can sense $\mathrm{Cu}^{2+}$ ion in much lower concentration than recommended by World Health Organization (WHO) in drinking water $(30 \mathrm{mM})$ over a wide $\mathrm{pH}$ range of 4 to 12 . Moreover, sensor (29) was also examined for sensing of different anions in similar condition because receptor having both phenolic and imine groups which can sense anions through hydrogen bonding. It was observed that upon addition of 600 equivalents of $\mathrm{F}^{-}$ion, 29 showed significant spectral changes consistent with color changes from yellow to orange while other anions exhibited no change in absorption spectrum.

A duel colorimetric sensor 2-(3-nitro-2-oxo-2H-chromen-4ylamino)-3-aminomaleonitrile (30) was developed for the detection of $\mathrm{Al}^{3+}$ and $\mathrm{F}^{-}$ions with detection limit of $38.2 \mu \mathrm{M}$ for $\mathrm{Al}^{3+}$ ion. ${ }^{61}$ The sensor showed absorption peaks at 250, 334, and $432 \mathrm{~nm}$ which were decreased and a new peak at $302 \mathrm{~nm}$ was appeared on stepwise addition of $\mathrm{Al}^{3+}$ ion with significant colorimetric changes over other competitive ions like $\mathrm{Ga}^{3+}$ and $\mathrm{In}^{3+}$ in aqueous medium. The color changes might be attributed to binding of $\mathrm{Al}^{3+}$ ion with $\mathrm{NH}$ and $\mathrm{NH}_{2}$ groups of the receptor which result weakened ICT transition of sensor 30 (Fig. 16). Interestingly, it was found that sensor can be recycled and reused after treatment with ethylenediaminetetraacetic acid (EDTA). On the other hand, it was found that 30 showed selective colorimetric sensing towards $\mathrm{F}^{-}$ion because of fluoride ion induced deprotonation process which led decrease in the intramolecular charge transfer.

A ninhydrin functionalized diaminomalenonitrile based sensor (31) was developed by condensation reaction between 2,3-diaminomalenonitrile and ninhydrin. ${ }^{62}$ Interestingly, sensor (31) exhibited blue color on simultaneous addition of $\mathrm{Hg}^{2+}$ and $\mathrm{CH}_{3} \mathrm{COO}^{-} / \mathrm{F}^{-}$ions whereas addition of either $\mathrm{Hg}^{2+}$ or $\mathrm{CH}_{3} \mathrm{COO}^{-} / \mathrm{F}^{-}$showed purple colour. These interesting switching behavior of sensor $\mathbf{3 1}$ was specific in terms of theses ion pairs as no other ion pairs exhibited similar behavior. These unique colorimetric behavior was further proven by UV-visible spectroscopy in which receptor $\mathbf{3 1}$ exhibited absorption peaks at $535 \mathrm{~nm}$ and $310 \mathrm{~nm}$ due to intramolecular charge transfer (ICT) band and sharp $\pi-\pi$ transition band respectively. The addition of 2.0 equivalent of $\mathrm{HgCl}_{2}$ led no change in absorption spectrum as well as no visible color change. Interestingly, purple color of the receptor changed to blue as 2.0 equivalent of $\mathrm{CH}_{3} \mathrm{COO}^{-} / \mathrm{F}^{-}$was added to the same solution. Along with this, in UV-vis spectrum of receptor, peak at $535 \mathrm{~nm}$ shifted to $590 \mathrm{~nm}$ while peak at $310 \mathrm{~nm}$ remained almost unaffected.

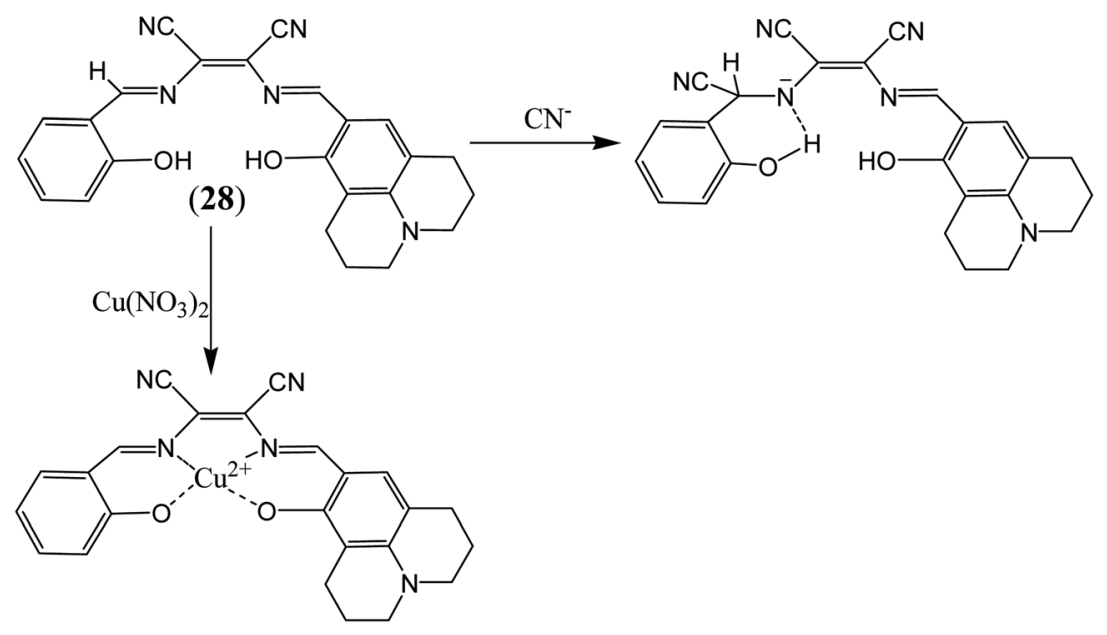

Fig. 14 The sensing mechanism for sensor (28) for $\mathrm{Cu}^{2+}$ and $\mathrm{CN}^{-}$ion. 

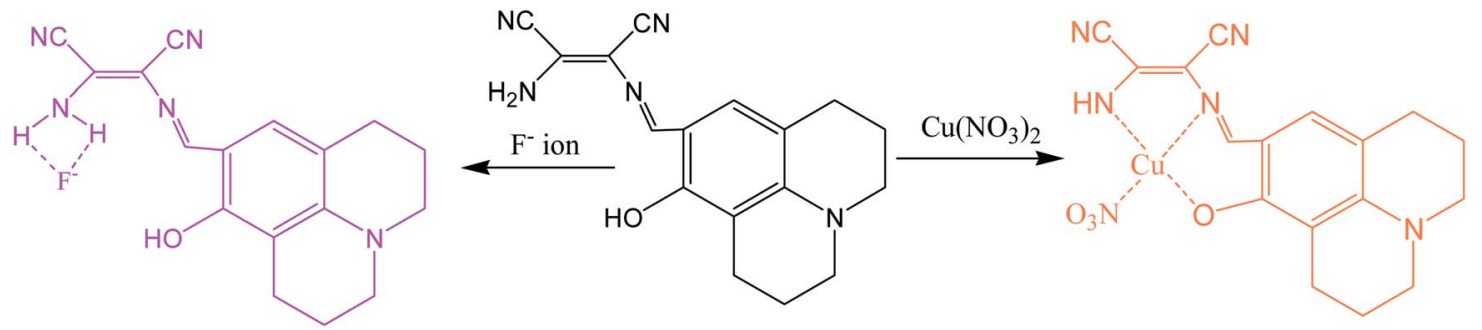

Fig. 15 The sensing mechanism for sensor (29) for $\mathrm{Cu}^{2+}$ ion and $\mathrm{F}^{-}$ion.

Other anions like $\mathrm{H}_{2} \mathrm{PO}_{4}^{-}, \mathrm{Cl}^{-}, \mathrm{Br}^{-}, \mathrm{C}_{6} \mathrm{H}_{5} \mathrm{COO}^{-}$were not able to produce similar synergistic behavior with $\mathrm{Hg}^{2+}$ in terms of UVvis spectral pattern or colorimetric responses.<smiles></smiles>

Some DAMN based chemosensor molecules were designed in which sensing of both metal and anion were carried out through metal ion displacement approach. For example, a quinoline-based chemosensor (32) was developed for sequential sensing of $\mathrm{Cu}^{2+}$ and $\mathrm{CN}^{-}$ions. ${ }^{63}$ The sensor (32) exhibited remarkable colorimetric change with significant shift in absorption maxima from $390 \mathrm{~nm}$ to $537 \mathrm{~nm}$ on treatment with $\mathrm{Cu}^{2+}$ ion in aqueous solution. Therefore, sensor molecule<smiles>N#C/C(N)=C(\N)C#N</smiles>

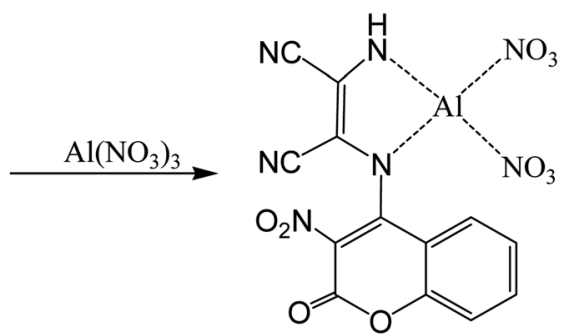

30

Fig. 16 The sensing mechanism for sensor (30) for $\mathrm{Al}^{3+}$ ion. was used for preparing test strips for monitoring of $\mathrm{Cu}^{2+}$ ion. In addition, $32-\mathrm{Cu}^{2+}$ adduct was used for sequential monitoring of cyanide anion with dramatic colour change based on copper ion displacement mechanism as shown in Fig. 17.

By using similar approach, Singaravadivel et al. utilized phenothiazine moiety as fluorophore for synthesis of diaminomalenonitrile based chromo-fluorescent probe $\left[3,3^{\prime}-\right.$ $\left(\left(\left(1 Z, 1^{\prime} Z\right)-(10\right.\right.$-hexyl-10H-phenothiazine-3,7-diyl)bis(methanylylidene))bis(azanylylidene))bis(2-aminomaleonitrile)] (33) for sensing of toxic $\mathrm{Hg}^{2+}$ and $\mathrm{S}^{2-}$ ions. ${ }^{64}$ Synthesized probe (33) exhibited emission peak at $575 \mathrm{~nm}$ upon excitation at $450 \mathrm{~nm}$ in ethanol/water solvent system. Addition of $\mathrm{Hg}^{2+}$ ion lead quenching of emission peak at $575 \mathrm{~nm}$ along with visible colorimetric change from yellow to brown whereas other ions such as $\mathrm{Mn}^{2+}, \mathrm{Cu}^{2+}, \mathrm{Pb}^{2+}, \mathrm{Cd}^{2+}, \mathrm{Co}^{2+}, \mathrm{Zn}^{2+}, \mathrm{Fe}^{3+}, \mathrm{Ag}^{+}, \mathrm{Mg}^{2+}, \mathrm{Al}^{3+}$, $\mathrm{Cr}^{3+}, \mathrm{Ni}^{2+}, \mathrm{Na}^{+}$and $\mathrm{K}^{+}$, did not lead any change in the emission peak at $575 \mathrm{~nm}$. This quenching behavior was ascribed by inhabitation of internal charge transfer process from phenothiazine moiety to DAMN unit after binding with $\mathrm{Hg}^{2+}$ ion. Further, it was observed that quenched fluorescence can be restored by adding 1.0 equivalent of $\mathrm{Na}_{2} \mathrm{~S}$ solution. This is explained by the fact that mercury ions have high affinity for sulfur hence $\mathrm{S}^{2-}$ removed $\mathrm{Hg}^{2+}$ ion from $32-\mathrm{Hg}^{2+}$ complex with regaining of emission peak at $575 \mathrm{~nm}$ (Fig. 18). It was also demonstrated that probe can be successfully used for selective imaging of $\mathrm{Hg}^{2+}$ and $\mathrm{S}^{2-}$ in living cells.

\section{DAMN based chemosensor for sensing of reactive oxygen species}

Reactive oxygen species (ROS) have significant role in regulation of biological and pathological processes. Moderate level of ROS is crucial for normal cell functions. ${ }^{65,66}$ However, the overproduction of ROS increases oxidative stress, causing many detrimental effects on biological molecules such as proteins,

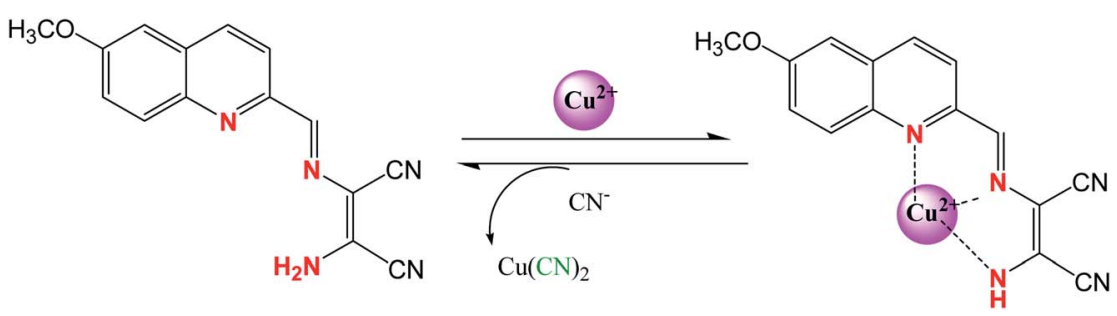

Fig. 17 The sequential sensing mechanism for sensor (32) for $\mathrm{Cu}^{2+}$ an $\mathrm{CN}^{-}$ion. 


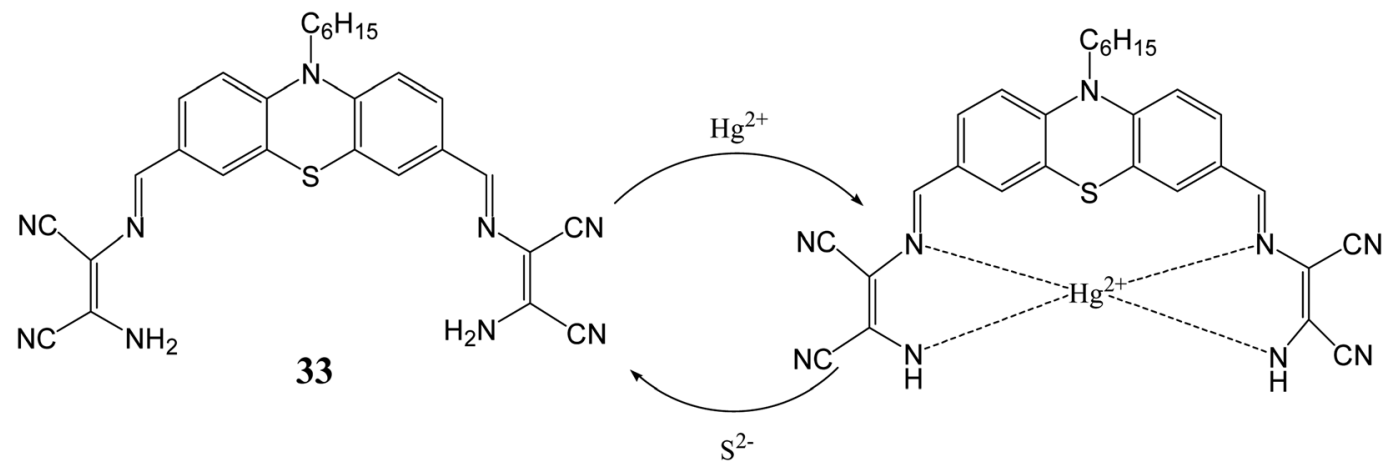

Fig. 18 The sensing mechanism for sensor (33) for $\mathrm{Hg}^{2+}$ and $\mathrm{S}^{2-}$ ion.

phospholipids, RNA and DNA, which leads to inhibition of various protein functions and contributes to the progression of aging and numerous incurable human diseases. ${ }^{67-72}$ Various types of reactive oxygen species such as hydrogen peroxide
$\left(\mathrm{H}_{2} \mathrm{O}_{2}\right)$, superoxide $\left(\mathrm{O}_{2}^{-}\right)$, hypochlorous acid ( $\left.\mathrm{HOCl}\right)$, hydroxyl radical $\left(\mathrm{HO}^{*}\right)$, singlet oxygen and lipid hydro-peroxides are formed as natural by-product of the normal metabolism of oxygen. Among these ROS, hypochlorite $\left(\mathrm{ClO}^{-}\right)$is an important

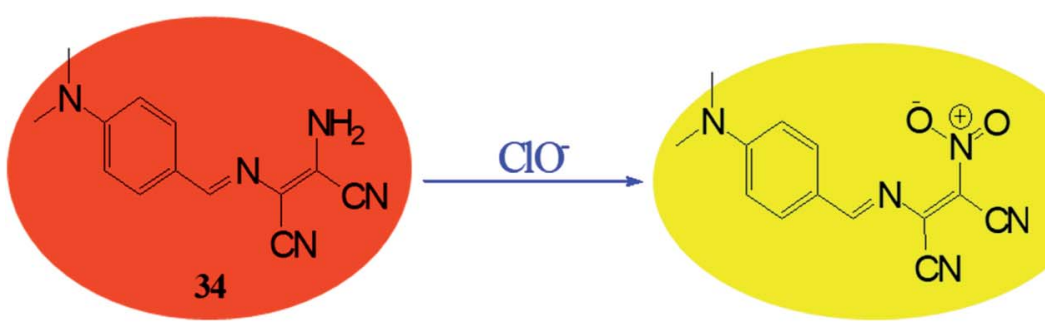

Fig. 19 The formation of nitroso compound of sensor (34) on interaction with $\mathrm{ClO}^{-}$ion.

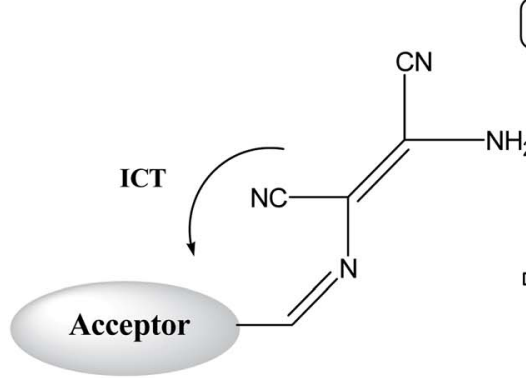

ICT on, Fluorescent off

\section{Conventional approach}
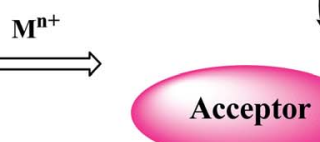

ICT off, Fluorescent on

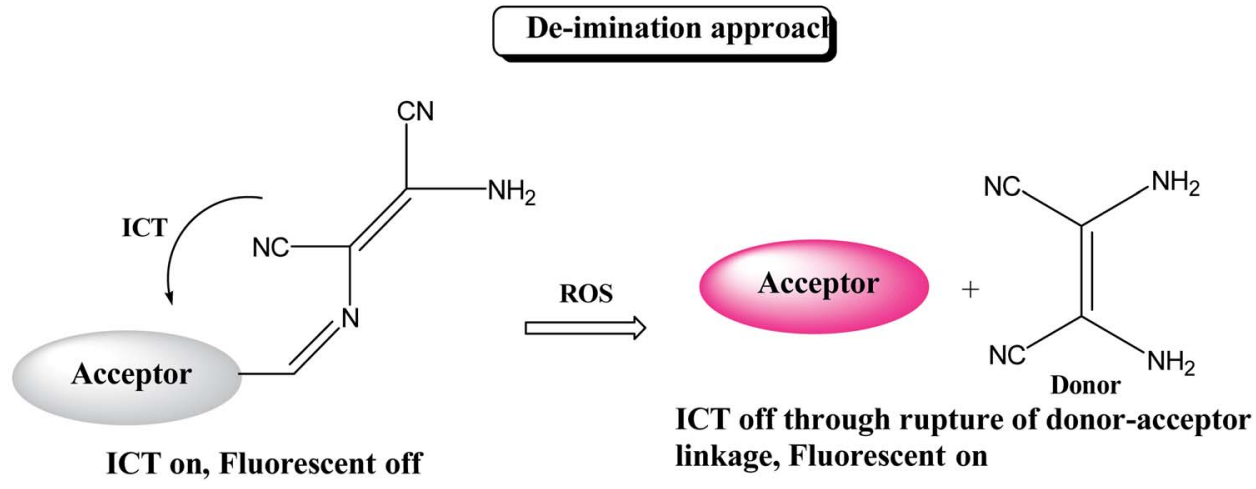

Scheme 1 General approach for sensing of analytes by DAMN derived sensor molecules. 
Table 1 Comparison of different molecular probe for the detection of $\mathrm{ClO}^{-}$

\section{Entry}<smiles>N#C/C(N)=C(\C#N)N=Cc1cc2cc3c4c(c2oc1=O)CCCN4CCC3</smiles>

2<smiles>CC(F)(F)n1c2ccc(C=NC(C#N)=C(N)C#N)cc2c2cc(C=N/C(C#N)=C(/N)C#N)ccc21</smiles>

3<smiles>N#CC(N)=C(C#N)N=Cc1ccc2ccc3ccc(C=NC(C#N)=C(N)C#N)nc3c2n1</smiles>

4<smiles>N#C/C(N)=C(\N)N=Cc1ccc2ccc3cccc4ccc1c2c34</smiles>

$$
2.83 \times 10^{-6} \mathrm{M}
$$

$1.40 \times 10^{-8} \mathrm{M}$

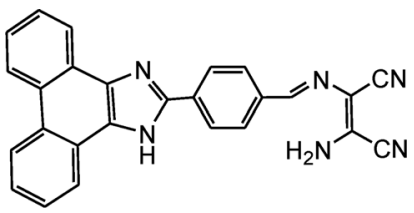<smiles>CN(C)c1ccc2c(c1)CCC1C=C(c3cccc(C=NC(N)=C(N)C#N)c3O)SC21</smiles><smiles>CN(C)c1ccc2c(-c3ccccc3C(=O)O)c3cc(/C=N\C(C#N)=C(N)C#N)c(=O)cc-3oc2c1</smiles>

8

9<smiles>COc1cccc2cc(C=N/C(C#N)=C(/N)C#N)cnc12</smiles><smiles>N#CC(N)=C(N)N=Cc1cccc(-c2nc3ccccc3o2)c1O</smiles>

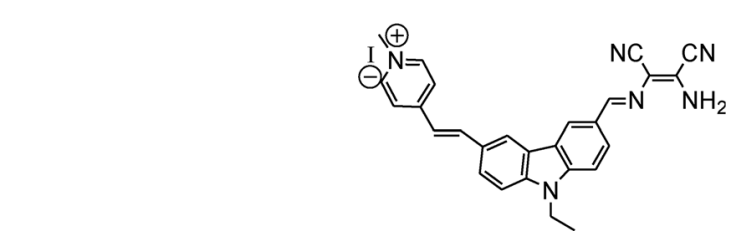

Detection limit

References

$1.07 \times 10^{-6} \mathrm{M}$

$3.30 \times 10^{-6} \mathrm{M}$

Goswami et al. ${ }^{82}$

Yang et al. ${ }^{83}$

Zhao et al. ${ }^{84}$

$1.50 \times 10^{-7} \mathrm{M}$

Ning et al. ${ }^{85}$

$2.88 \times 10^{-8} \mathrm{M}$

Zhang et al. ${ }^{86}$

$7.87 \times 10^{-7} \mathrm{M}$

Das et al. ${ }^{87}$

$8.00 \times 10^{-8} \mathrm{M}$

Chen et $a l .^{88}$

10

$2.00 \times 10^{-4} \mathrm{M} \quad$ Yuan et al. ${ }^{80}$

Goswami et al. ${ }^{81}$

rar

$$
\text { Zhao et al. }
$$




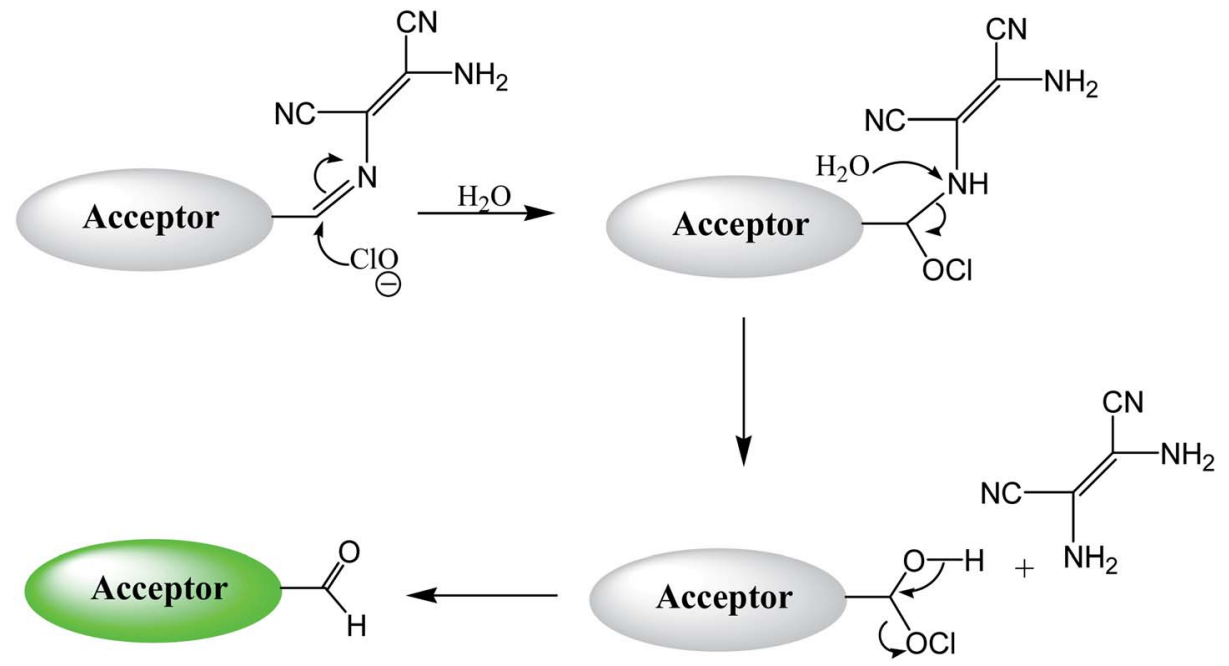

Scheme 2 Sensing mechanism of hypochlorite by molecular probe.

ROS, it is also extensively used in our daily life, such as a disinfectant for drinking water, household bleach etc. Hypochlorite is produced in living organisms by hydrogen peroxide and chloride ions through a chemical reaction catalyzed by the enzyme myeloperoxidase (MPO) and protect against the invasion of pathogens. ${ }^{73-78}$ Due to crucial role of hypochlorite various research groups are involved in developing molecular probes for easy and selective detection of hypochlorite ion. Since the colorimetric and fluorometric detections are easy and convenient than other analytical techniques, most efforts were put on developing colorimetric and fluorometric sensors. These sensors worked mainly on two approaches: (i) oxidation of functional group attached with signalling unit of sensor; (ii) cleavage of linkage between donor and acceptor group. On the basis of these approaches, there are reports where DAMN based chemosensors are used to detect $\mathrm{ClO}^{-}$ion. For example, a simple diaminomaleonitrile based probe (34) synthesized by condensation reaction of 4-(dimethylamino)benzaldehyde and diaminomaleonitrile for ratiometric detection of $\mathrm{ClO}^{-}$ion. ${ }^{79} \mathrm{~A}$ sharp colour change from the canary yellow to red upon interaction with $\mathrm{ClO}^{-}$ion was advantage of this probe (34) for sensing of $\mathrm{ClO}^{-}$ion through naked eye. The fluorometric analysis of the probe was performed and it showed that emission peak at $521 \mathrm{~nm}$ was decreases and a new emission peak evolved at $635 \mathrm{~nm}$ with addition of $\mathrm{ClO}^{-}$solution. The intensity ratio of these two peaks was used for ratiometric detection of $\mathrm{ClO}^{-}$ion. Interestingly, when comparing mass spectrometric and ${ }^{1} \mathrm{H}$ NMR data of sensor (34) solution and sensor in presence $\mathrm{ClO}^{-}$ion solution revealed oxidation of amino group of DAMN which resulted in the formation of nitro compound as shown in Fig. 19.

Generally, DAMN based sensors have been developed by conjugating of electron-withdrawing groups (acceptor) with electron-donating group (donor) via imine linkage. An intramolecular charge transfer (ICT) occurs from DAMN (donor) to acceptor upon excitation by light which make sensor nonfluorescent. The electron-donating DAMN binds with cation which inhibit intramolecular charge transfer (ICT) due to the loses of electron-donating ability of DAMN and make the sensor cation adduct fluorescent. In an another approach, the fluorescence intensity can be enhanced by breaking the imine linkage between DAMN and acceptor moiety by the specific analyte and the recovered parent acceptor moiety (fluorophore dye) rejuvenate its original intense emission peaks as depicted in Scheme 1.

By using virtue of this approach, different research groups have developed interesting sensor molecules for detection of hypochlorite ion by conjugating DAMN (donor) with different acceptors (fluorophores) like benzoxazole, carbazole, quinolone, phenanthroline, naphthalenone, pyrene, carbazole, coumarin derivatives, xanthene dyes and phenanthroimidazole moiety as shown in Table 1. Analysis of LOD values of sensors reported in Table 1 indicated that most of these sensors can detect $\mathrm{ClO}^{-}$in the range of $10^{-6}$ to $10^{-8} \mathrm{M}$ and DAMN attached to extended conjugated system exhibited lower detection limit. It was also observed that most of these sensor molecules exhibited low cytotoxic effect on cells thus can be used in imaging of living cells. In most cases the mechanism involves the attachment of $\mathrm{ClO}^{-}$ion to the carbon atom of imine group followed by nucleophilic attack of $\mathrm{H}_{2} \mathrm{O}$ to form corresponding aldehyde and DAMN as shown in Scheme 2. The sensing mechanism was confirmed by NMR titration experiments, mass spectrum analysis and DFT calculations by most of research groups. ${ }^{80,81,87}$

\section{Conclusion}

Many approaches have been evolved to design effective molecular sensors capable of selective and sensitive sensing of cationic, anionic and neutral guest species with significant optical response. Many molecular structures with chromo sensing ability have been reported consisting of signal generating and binding sites. In these chemosensors, optical reporter is simply conjugated either directly or via short covalent spacer 
to binding sites which upon interaction with guest species produces changes in photophysical properties of the optical reporters. This review demonstrates how the field of DAMN based chemosensor research have flourished over a period of last 25 years. We have attempted to summarise research articles highlighting the use of 2,3-diaminomalenonitrile (DAMN) in the field of optical and colorimetric sensor for ionic and reactive oxygen species in this review. It is clear from this review that DAMN derived sensor molecules have ability to sense cations, anion and reactive oxygen species selectively in aqueous and other competitive media with detection limit of $10^{-6}$ to $10^{-8} \mathrm{M}$ range. Further, availability of vast number of chromophore and fluorophore molecules can be employed to generate new sensors for efficient detection of targeted analytes. We hope that area of DAMN based sensors research will continue to thrive.

\section{Conflicts of interest}

There are no conflicts to declare.

\section{Acknowledgements}

R. S. and A. A. and Aruna acknowledge for Department of Chemistry, Manipal University Jaipur for providing laboratory and other facilities during their work. S. S. and B. R. acknowledges MUJ for teaching assistantship.

\section{References}

1 A. Collet, Comprehensive supramolecular chemistry, Pergamon Press, Oxford, 1996, vol. 2.

2 Supramolecular Chemistry, ed. P. A. Gale, John Wiley \& Sons, 2012.

3 V. Martí-Centelles, M. D. Pandey, M. I. Burguete and S. V. Luis, Chem. Rev., 2015, 115, 8736-8834.

4 C. D. Gutsche, Calixarenes: monographs in supramolecular chemistry, ed. J. F. Stoddart, The Royal Society of Chemistry, Cambridge, UK, 1989.

$5 \mathrm{~J}$. B. Wittenberg and L. Isaacs, Complementarity and Preorganization, John Wiley \& Sons, 2012.

6 Comprehensive Supramolecular Chemistry, ed. D. D. MacNicol and F. T. R. Bishop, Pergamon, 1999, vol. 6.

7 R. N. Dsouza, U. Pischel and W. M. Nau, Chem. Rev., 2011, 111, 7941-7980.

8 S. Kubik, Chem. Soc. Rev., 2010, 39, 3648-3663.

9 T. Gunnlaugsson, M. Glynn, G. M. Tocci, P. E. Kruger and F. M. Pfeffer, Coord. Chem. Rev., 2006, 250, 3094-3117.

10 C. Suksai and T. Tuntulani, Chem. Soc. Rev., 2003, 32, 192202.

11 X. Chen, Y. Zhou, X. Peng and J. Yoon, Chem. Soc. Rev., 2010, 39, 2120-2135.

12 L. E. Santos-Figueroa, M. E. Moragues, E. Climent, A. Agostini, R. Martinez-Manez and F. Sancenon, Chem. Soc. Rev., 2013, 42, 3489-3613.

13 H. Zhu, J. Fan, B. Wang and X. Pang, Chem. Soc. Rev., 2015, 44, 4337-4366.
14 L. You, D. Zha and E. V. Anslyn, Chem. Rev., 2015, 115, 78407892.

15 C. MacDonagh, C. S. Burke and B. D. MacCraith, Chem. Rev., 2008, 108, 400-422.

16 J. Wu, B. Kwon, W. Liu, E. V. Anslyn, P. Wang and J. S. Kim, Chem. Rev., 2015, 115, 7893-7943.

17 H. N. Kim, W. X. Ren, J. S. Kim and J. Yoon, Chem. Soc. Rev., 2012, 41, 3210-3244.

18 T. W. Bell and N. M. Hext, Chem. Soc. Rev., 2004, 33, 589-598.

19 Y. Ohtsuka, J. Org. Chem., 1978, 43, 3231-3234.

20 Y. Yamada, N. Nagashima, Y. Iwashita, A. Nakamura and I. Kumashiro, Tetrahedron Lett., 1968, 43, 4529-4532.

21 R. A. Sanchez, J. P. Ferbis and L. E. Orgel, J. Mol. Biol., 1967, 30, 223-253.

22 M. J. MacLachlan, M. K. Park and L. K. Thompson, Inorg. Chem., 1996, 35, 5492-5499.

23 H. Khanmohammadi and A. Abdollahi, Dyes Pigm., 2012, 94, 163-168.

24 A. Al-Azmi, A. Z. A. Elassar and B. L. Booth, Tetrahedron, 2003, 59, 2749-2763. Reference therein.

25 R. Faust, Eur. J. Org. Chem., 2001, 15, 2797-2803.

26 O. Lange, Eur. J. Inorg. Chem., 1873, 6, 99-101.

27 C. Bedel, Comptes rendus de l'Académie des Sciences, 1923, 176, 168-171.

28 R. L. Webb, S. Frank and W. C. Schneider, J. Am. Chem. Soc., 1955, 77, 3491-3493.

29 H. Bredereck, G. Schmotzer and H. J. Becher, Eur. J. Org. Chem., 1956, 600, 87-95.

30 H. Bredereck and G. Schmotzer, Liebigs Ann., 1956, 600, 95108.

31 E. Gryszkiewicz-Trochimowski, Roczniki Chem., 1928, 8, 165; Chem. Abstr., 1928, 22, 4475.

32 B. R. Penfold and W. Lipscomb, Acta Crystallogr., 1961, 14, 589-597.

33 K. L. Krik, Biochemistry of Halogens and Inorganic Halides, Plenum Press, New York, 1991, p. 591.

34 S. Sarveswari, A. J. Beneto and A. Siva, Sens. Actuators, B, 2017, 245, 428-434.

35 M. J. Kim, R. Manivannan, I. J. Kim and Y.-A. Son, Sens. Actuators, B, 2017, 253, 942-948.

36 K. Keshav, P. Torawane, M. K. Kumawat, K. Tayade, S. K. Sahoo, R. Srivastava and A. Kuwar, Biosens. Bioelectron., 2017, 92, 95-100.

37 D. Jeyanthi, M. Iniya, K. Krishnaveni and D. Chellappa, Spectrochim. Acta, Part A, 2015, 136, 1269-1274.

38 S. Bartocci, F. Sabat, R. Bosque, F. Keymeulen, K. Bartik, L. Rodríguez and A. D. Cort, Dyes Pigm., 2016, 135, 94-101.

39 J. J. R. Frausto da Silva and R. J. P. Williams, The Biological Chemistry of the Elements: The Inorganic Chemistry of Life, Oxford University Press, New York, 1991, p. 344.

40 H. Zhou, J. Wang, Y. Chen, W. Xi, Z. Zheng, D. Xu, Y. Cao, G. Liu, W. Zhu, J. Wu and Y. Tian, Dyes Pigm., 2013, 98, 1-10.

41 H. Lan, B. Liu, G. Lv, Z. Li, X. Yu, K. Liu, X. Cao, H. Yang, S. Yang and T. Yi, Sens. Actuators, B, 2012, 173, 811-816.

42 X.-Y. Xue, D.-Y. Jiang, C. Feng, H. Zhang, Z.-F. Wang and H. Zhao, Inorg. Chem. Commun., 2017, 86, 258-261. 
43 Q. Bing, L. Wang, D. Li and G. Wang, Spectrochim. Acta, Part A, 2018, 202, 305-313.

44 J. W. Liu and Y. Lu, J. Am. Chem. Soc., 2007, 129, 9838-9839. 45 J. Ma, R. Sheng, J. Wu, W. Liu and H. Zhang, Sens. Actuators, B, 2014, 197, 364-369.

46 S. Swami, A. Agarwala, V. P. Verma and R. Shrivastava, ChemistrySelect, 2017, 2, 11474-11481.

47 S. Swami, D. Behera, A. Agarwala, V. P. Verma and R. Shrivastava, New J. Chem., 2018, 42, 10317-10326.

48 S. Swami, A. Agarwala, B. Malik and R. Shrivastava, J. Chem. Sci., 201, 128, 1451-1457.

49 H. M. Chawla, S. N. Sahu, R. Shrivastava and S. Kumar, Tetrahedron Lett., 2012, 53, 2244-2247.

50 H. M. Chawla, R. Shrivastava, S. N. Sahu, S. Kumar and S. Upreti, Supramol. Chem., 2012, 24, 672-683.

51 H. M. Chawla and R. Shrivastava, J. Inclusion Phenom. Macrocyclic Chem., 2009, 65, 255-263.

52 S. Swami, A. Agarwala, D. Behera and R. Shrivastava, Sens. Actuators, B, 2018, 260, 1012-1017.

53 Y. He, J. Yin and G. Wang, Chem. Heterocycl. Compd., 2018, 54, 146-152.

54 S. Goswami, S. Das and K. Aich, Tetrahedron Lett., 2013, 54, 4620-4623.

55 S. R. Patil, A. S. Choudhary and N. Sekar, New J. Chem., 2016, 40, 6803-6811.

56 Y. Huo, S. Wang, T. Lu, C. Pan, Y. Lu, X. Yang, D. Hu and S. Hu, RSC Adv., 2016, 6, 5503-5511.

57 J. Cheng, Y. Zhang, X. Ma, X. Zhou and H. Xiang, Chem. Commun., 2013, 49, 11791-11793.

58 M. A. Kobaisi, S. V. Bhosale, K. Latham, A. M. Raynor and S. V. Bhosale, Chem. Rev., 2016, 116, 11685-11796.

59 T. G. Jo, Y. J. Na, J. J. Lee, M. M. Lee, S. Y. Lee and C. Kim, Sens. Actuators, B, 2015, 211, 498-506.

60 T. G. Jo, Y. J. Na, J. J. Lee, M. M. Lee, S. Y. Lee and C. Kim, New J. Chem., 2015, 39, 2580-2587.

61 G. J. Park, H. Y. Jo, K. Y. Ryu and C. Kim, $R S C A d v .$, 2014, 4, 63882-63890.

62 A. Kumar, V. Kumar and K. K. Upadhyay, Tetrahedron Lett., 2011, 52, 6809-6813.

63 C. Wu, J. Wang, J. Shen, C. Zhang, Z. Wu and H. Zhou, Tetrahedron, 2017, 73, 5715-5719.

64 K. M. Vengaian, C. D. Britto, K. Sekar, G. Sivaraman and S. Singaravadivel, RSC Adv., 2016, 6, 7668-7673.

65 C. C. Winterbourn, Nat. Chem. Biol., 2008, 4, 278-286.

66 I. L. Chapple, J. Clin. Periodontol., 1997, 24, 287-296.

67 R. A. Roberts, R. A. Smith, S. Safe, C. Szabo, R. B. Tjalkens and F. M. Robertson, Toxicology, 2010, 276, 85-94.
68 A. Zulli, Curr. Opin. Clin. Nutr. Metab. Care, 2011, 14, 57-60. 69 C. Sand, S. L. M. Peters, M. Pfaffendorf and P. A. Van Zwieten, Clin. Exp. Pharmacol., 2003, 30, 249-253.

70 T. Hasegawa, E. Malle, A. Farhood and H. Jaeschke, Am. J. Physiol.: Gastrointest. Liver Physiol., 2005, 289, G760-G767.

71 A. Daugherty, J. Dunn, D. Rateri and J. W. Heinecke, J. Clin. Invest., 1994, 94, 437-444.

72 S. Hammerschmidt, N. Buchler and H. Wahn, Chest, 2002, 121, 573-581.

73 S. M. Wu and S. V. Pizzo, Arch. Biochem. Biophys., 2001, 391, 119-126.

74 Y. Koide, Y. Urano, K. Hanaoka, T. Terai and T. Nagano, J. Am. Chem. Soc., 2011, 133, 5680-5682.

75 S. Sugiyama, K. Kugiyama, M. Aikawa, S. Nakamura, H. Ogawa and P. Libby, Arterioscler., Thromb., Vasc. Biol., 2004, 24, 1309-1314.

76 Y. W. Yap, M. Whiteman and N. S. Cheung, Cell. Signalling, 2007, 19, 219-228.

77 M. J. Steinbeck, L. J. Nesti, P. F. Sharkey and J. Parvizi, J. Orthop. Res., 2007, 25, 1128-1135.

78 E. A. Podrez, H. M. Abu-Soud and S. L. Hazen, Free Radical Biol. Med., 2000, 28, 1717-1725.

79 Y. Jiang, S. Wu, C. Jin, B. Wang and J. Shen, Sens. Actuators, $B, 2018,265,365-370$.

80 L. Yuan, W. Lin, J. Song and Y. Yang, Chem. Commun., 2011, 47, 12691-12693.

81 S. Goswami, S. Paul and A. Manna, Dalton Trans., 2013, 42, 10097-10101.

82 S. Goswami, S. Maity, A. C. Maitya and A. K. Das, Sens. Actuators, B, 2014, 204, 741-745.

83 Y. Yang, C. Gao, J. Chen, N. Zhang and D. Dong, Anal. Methods, 2016, 8, 805-809.

84 Y. Zhao, H. Lia, Y. Xue, Y. Rena and T. Hana, Sens. Actuators, $B, 2017,241,335-341$.

85 Y. Ning, J. Cui, Y. Lu, X. Wang, C. Xiao, S. Wu, J. Li and Y. Zhang, Sens. Actuators, B, 2018, 269, 322-330.

86 Y. Zhang, L. Ma, C. Tang, S. Pan, D. Shi, S. Wang, M. Li and Y. Guo, J. Mater. Chem. B, 2018, 6, 725-731.

87 S. Das, K. Aich, L. Patra, K. Ghoshal, S. Gharami, M. Bhattacharyya and T. K. Mondal, Tetrahedron Lett., 2018, 59, 1130-1135.

88 L. Chen, S. J. Park, D. Wu, H. M. Kim and J. Yoon, Dyes Pigm., 2018, 158, 526-532.

89 Y. Feng, S. Li, D. Li, Q. Wang, P. Ning, M. Chen, X. Tian and X. Wang, Sens. Actuators, B, 2018, 254, 282-290. 